\title{
Ddp1 cooperates with Ppx1 to counter a stress response initiated by non-vacuolar polyphosphate
}

\author{
Liam McCarthy ${ }^{1,2}$, Iryna Abramchuk ${ }^{2,3}$, Gamal Wafy ${ }^{1,2}$, Alix Denoncourt ${ }^{1,2}$, Mathieu Lavallée- \\ Adam $^{2,3}$ \& Michael Downey ${ }^{1,2,4}$ \\ 1. Department of Cellular \& Molecular Medicine, University of Ottawa, Ottawa, Ontario, Canada \\ 2. Ottawa Institute of Systems Biology, University of Ottawa, Ottawa, Ontario, Canada \\ 3. Department of Biochemistry, Microbiology \& Immunology, University of Ottawa, Ottawa, Ontario, Canada \\ 4. Corresponding author: mdowne2@uottawa.ca
}

Running Title: Cellular response to non-vacuolar polyP

Keywords: Polyphosphate, proteomics, polyP, stress response, Msn2, PPK, Vtc4, Hog1, Yak1 


\section{ABSTRACT:}

In diverse cells from bacterial to mammalian species, inorganic phosphate is stored in long chains called polyphosphates (polyP). These near universal polymers, ranging from 3 to thousands of phosphate moieties in length, are associated with molecular functions including energy homeostasis, protein folding, and cell signaling. In many cell types, polyphosphate is concentrated in subcellular compartments or organelles. In the budding yeast $S$. cerevisiae, polyP synthesis by the membrane-bound VTC complex is coupled to its translocation into the lumen of the vacuole, a lysosome-related organelle, where it is stored at high concentrations. In contrast, ectopic expression of bacterial polyphosphate kinase, PPK, results in the toxic accumulation of polyP outside of the vacuole. In this study, we used label-free mass spectrometry to investigate the mechanisms underlying this toxicity. We find that PPK expression results in the activation of a stress response mediated in part by the Hog1 and Yak1 kinases, and Msn2/Msn4 transcription factors. This response is countered by the combined action of the Ddp1 and Ppx1 polyphosphatases that function together to counter polyP accumulation and downstream toxicity. In contrast, ectopic expression of previously proposed mammalian polyphosphatases did not impact PPK-mediated toxicity in this model, suggesting either that these enzymes do not function directly as polyphosphatases in vivo or that they require co-factors unique to higher eukaryotes. Our work provides a mechanistic explanation for why polyP accumulation outside of lysosome-related organelles is toxic. Further, it serves as a resource for exploring how polyP may impact conserved biological processes at a molecular level. 


\section{INTRODUCTION:}

Inorganic phosphates can be joined in linear chains that range from 3 to 1000s of residues in length. These polymers, called polyphosphate or 'polyP', have been implicated in diverse biological processes spanning both prokaryotic and eukaryotic species. In the budding yeast $S$. cerevisiae, polyP is synthesized by the vacuolar transporter chaperone (VTC) complex ${ }^{[1]}$. The VTC complex is composed of the catalytic subunit Vtc4, along with Vtc1 and one of either Vtc2 or Vtc $3^{[1]}$. Cells mutated for Vtc4, Vtc1, or both Vtc2 and Vtc3 have no detectable polyphosphate ${ }^{[2]}$. An accessory subunit called Vtc5 increases the activity of the complex but is not strictly required for polyP synthesis ${ }^{[3]}$. The majority of the VTC complex localizes to the membrane of the yeast vacuole, a type of lysosome-related organelle (LRO) ${ }^{[1]}$. The VTC complex spans the vacuolar membrane and synthesises polyP chains by hydrolyzing the gamma phosphate of cytoplasmic ATP, adding it to growing polyP chains that are simultaneously translocated into the vacuole lumen ${ }^{[4]}$. Vacuolar polyP comprises the majority of total cellular polyP stores exceeding $10-20 \%$ of the dry weight ${ }^{[2,5]}$. Other areas of the cell beyond the vacuole, including the plasma membrane, cytoplasm, and mitochondria have lower levels of polyP. PolyP is also found in the nucleus, although the reported levels vary drastically ${ }^{[2]}$. These variations are likely due to differences in growth conditions, as well as differences in the method of sample preparation and detection. Whether polyP outside of the vacuole is synthesized locally or somehow transported from polyP stores that first accumulate in the vacuole lumen is unknown. Although some VTC proteins localize in part to the plasma membrane and/or the endoplasmic reticulum $^{[1,6]}$, it is unknown if these pools of VTC proteins participate in polyP synthesis.

The subcellular enrichment of polyP is conserved in higher eukaryotes ${ }^{[7]}$. For example, in human myeloma cells ${ }^{[8]}$, and various cancer cell lines treated with cisplatin ${ }^{[9]}$, polyP accumulates 
in the nucleolus. In platelets it is concentrated in LROs called dense granules ${ }^{[10]}$. The localization of polyP to such hotspots likely promotes specific functions. In yeast, vacuolar polyP is important for phosphate homeostasis ${ }^{[11]}$ and vacuole fusion ${ }^{[12]}$. PolyP released from dense granules following injury interacts directly with specific clotting factors to promote blood coagulation $^{[10,13]}$. In contrast, less is known about whether there are physiological reasons why polyP in some areas of the cell must be kept low.

Unlike the VTC complex, ectopic expression of Escherichia coli (E. coli) polyphosphate kinase (called PPK) in yeast results in accumulation of polyP outside of the vacuole and this correlates with slow growth, altered cellular morphology, and dramatic sensitivity to the translation inhibitor cycloheximide and mTOR inhibitor rapamycin ${ }^{[4,14]}$. The amount of polyP made by PPK is at most $20 \%$ of that produced by VTC ${ }^{[4]}$, and PPK-induced toxicity is observed both in wild-type and $v t c 4 \Delta$ cells $^{[14]}$. Together, these data point to the location of PPKsynthesized polyP, rather than changes in the total amount, as the driving force behind the observed toxicity. Finding the mechanisms underlying this toxicity will provide a foundation for better understanding the spatial and temporal regulation of polyP metabolism in eukaryotic cells.

Here, we use label-free mass spectrometry to determine why PPK expression and the concomitant accumulation of non-vacuolar polyP is toxic in yeast. Our results demonstrate that PPK-expressing cells remodel their proteome with changes to protein networks controlling fundamental aspects of metabolism. In follow-up work, we present evidence that a Yak1/Hog1Msn2/4 pathway limits viability in these cells. Finally, we demonstrate that polyP accumulation outside the vacuole is countered by the combined activities of the endopolyphosphatase Ddp1 and the exopolyphosphatase Ppx1 that work together to degrade long-chain polyP synthesized by PPK. Our results provide an explanation for why polyP is sequestered, elaborate functions for 
bioRxiv preprint doi: https://doi.org/10.1101/2022.02.02.478728; this version posted February 2, 2022. The copyright holder for this preprint (which was not certified by peer review) is the author/funder, who has granted bioRxiv a license to display the preprint in perpetuity. It is made available under aCC-BY-NC 4.0 International license.

polyphosphatases outside the vacuole, and suggest new avenues for exploring polyP functions at the molecular level. 


\section{RESULTS:}

\section{Remodelling of the yeast proteome in response to ectopic PPK expression:}

To determine why PPK expression and the accumulation of non-vacuolar polyP is toxic in yeast, we used label-free mass spectrometry to survey changes to the proteome in strains expressing PPK versus empty vector control. Our initial experiments were carried out in a vtc $4 \Delta$ background, which enabled us to confirm the production of the polyP in each isolate used for analysis, as judged by the lysine polyphosphorylation of Fpr3 protein ${ }^{[14]}$ (Supplementary Fig. 1). The polyP made by PPK in yeast was of the long-chain type, similar to that produced by $E$. coli under starvation (Fig. 1A). Total protein from 5 isolates of control and 5 isolates of PPKexpressing cells was isolated using an SDS-lysis protocol prior to trypsinization and MS/MS analysis using a Thermo Scientific Q Exactive Plus Orbitrap mass spectrometer (Fig. 1B). As expected, peptides from bacterial PPK were detected only in the PPK-expressing strains (Supplementary Table S1). At an FDR-adjusted $p$-value $(p)<0.05$ level, 8 proteins were deemed significantly upregulated, while 6 were downregulated (Fig. 1C and 1D). An additional 24 proteins showed up- or downregulation with an associated statistical significance of $0.05 \leq p$ $\leq 0.1$ (Fig. 1C). Finally, there were 2 proteins that were detected in all five replicates of the empty vector control, but not in any replicates of the PPK-expressing strains (Fig. 1D and

\section{Supplementary Table S1).}

\section{Vacuolar polyP does not impact the cellular response to PPK expression:}

To validate our proteomics dataset, we expressed up- or downregulated proteins as C-terminal 3FLAG fusions from their endogenous loci and transformed these strains with control or PPKexpressing vectors. We first carried out this analysis in a vtc $4 \Delta$ background, mirroring the 
conditions used for our mass spectrometry experiments. For differentially expressed proteins with a $p \leq 0.1$, we confirmed 6 of 6 upregulations chosen for analysis (e.g. Gcv1) and 3 of 4 downregulations chosen for analysis (e.g. Fet3, Hem13), for an overall confirmation rate of $90 \%$ (Fig. 2A and Supplementary Table S2). The validation of protein changes in both the $p<0.05$ and $p \leq 0.1$ ranges supports our use of the $p \leq 0.1$ cut-off for downstream bioinformatics analyses (see below). Notably, we also confirmed 5 of 6 differentially expressed proteins beyond the $p=0.1$ value range (Supplementary Table S2), highlighting the overall high quality of our dataset and the stringency of our statistical approach.

To test if these changes are influenced by the presence of vacuolar polyP, we repeated our western-blotting analyses in a wild-type strain (i.e. $V T C 4+$ ), with a confirmation rate of $86 \%$ $(p \leq 0.1$, Fig. 2B and Supplementary Table S2). This observation is consistent with our previous work demonstrating that PPK expression sensitizes cells to rapamycin and cycloheximide, regardless of VTC4 status $^{[14]}$. As suggested ${ }^{[4]}$, PPK is not simply replacing polyP that is missing in $v t c 4 \Delta$ cells. Instead, non-vacuolar polyP appears to have unique consequences for the cell. Finally, to test if the catalytic activity of PPK was required for the observed effects, we generated a mutant version of the enzyme where three histidine residues shown or proposed to be required for catalytic activity ${ }^{[15-17]}$ were mutated to alanine. This mutant enzyme did not produce detectable polyP in vivo (Fig. 2C). Further, it did not result in the same slow growth defects seen for wild-type PPK expression (Fig. 2D). For 8 of 8 candidates tested $(p \leq 0.1)$, mutant PPK did not impact protein levels (Fig. 2E and Supplementary Table S2). Altogether, our data confirm that PPK-expression impacts polyP levels independently of vacuolar polyP. Finally, we note that proteins encoded by the phosphate (PHO) regulon (e.g. Pho8, Pho86, Vtc2 $)^{[18]}$ did not show significant changes in PPK-expressing cells (Supplementary Table S1). 
Therefore, the effects of PPK expression are not easily explained by changes in phosphate signaling.

\section{Mis-regulation of proteins involved in fundamental metabolism in PPK-expressing cells:}

To identify molecular functions impacted by PPK expression we carried out a Gene Ontology ${ }^{[19]}$ enrichment analysis of mis-regulated proteins $(p \leq 0.1)$. We found a statistically significant enrichment $($ FDR-adjusted $p$-value $=0.036)$ of GO:0006082 - organic acid metabolic process (Supplementary Table S1). Mis-regulated proteins belonging to this group include those involved in glucose metabolism (Hxk2, Tdh3), B vitamin synthesis (Snz1, Fol2), and amino acid biogenesis or turnover (e.g. Aro3, Gcv1, Gln1) ${ }^{[20]}$. These changes suggest that polyP accumulation outside of the vacuole influences important aspects of primary metabolism. Using STRING $^{[21]}$ (Search Tool for the Retrieval of Interacting Genes/Proteins) to model protein interactions, we found that mis-regulated proteins involved in amino acid metabolism shared physical interactions with each other, and with 3 heat shock proteins (Hsp26, Hsp42, Hsp 104) ${ }^{[20]}$ that were also significantly mis-regulated with PPK expression (Figure 2F). The identification of heat shock proteins in this network is interesting in light of the proposed role of polyP itself as a molecular chaperone (See Discussion) ${ }^{[22]}$. Other heat shock or 'quality control' proteins misregulated in our dataset include Hsp12, Hsp104, and Snl1, a co-chaperone for Hsp70 ${ }^{[20]}$.

PolyP can function as an ion chelator, and recent work from the Jakob lab suggests that it can act as an inhibitor of the Fenton reaction, in which $\mathrm{Fe}^{2+}$ reacts with hydrogen peroxide to form reactive hydroxyl radicals ${ }^{[23]}$. Interestingly, we noted that a number of proteins misregulated with PPK expression are either involved in ion transport (e.g. Fet3, which oxidizes $\mathrm{Fe}^{2+}$ to $\mathrm{Fe}^{3+[24]}$ ) or require divalent ions as co-factors (e.g. Adh4, which requires zinc for its 
catalytic activity $\left.{ }^{[25]}\right)$. Genes encoding other mis-regulated proteins confer resistance to metal ions

(e.g. $H I S 1^{[26]}$ ), or are induced in response to metal deficiency (e.g. $A D H 4$, induced in response to low zinc $\left.{ }^{[27]}\right)$. While the toxicity associated with PPK expression was not impacted by the addition of various divalent cations $\left(\mathrm{Fe}^{2+}, \mathrm{Mg}^{2+}, \mathrm{Zn}^{2+}\right)$ to growth media (Supplementary Fig. 2), we cannot yet rule out that disruption of ion homeostasis impacts proteome changes independently of the overt toxicity observed in PPK-expressing cells.

\section{An Msn2/Msn4-dependent signaling pathway limits viability in PPK-expressing cells:}

We next used the Yeast Search for Transcriptional Regulators and Consensus Tracking (YEASTRACT ${ }^{[28]}$ ) tool to identify candidate transcription factors involved in the regulation of genes encoding proteins up- or down-regulated in our dataset (Fig. 3A). We were particularly interested in Msn2 (regulating $85 \%$ of hits) and its paralog Msn4 (regulating $74 \%$ of hits) for two reasons. First, these transcription factors are involved in the response to diverse cellular stresses via the activation of stress response element genes ${ }^{[29,30]}$ (Fig. 3B). Second, the constitutive activation of Msn2 is associated with slow growth ${ }^{[31,32]}$. We reasoned that misregulation of Msn2 and/or Msn4 impact cell growth and/or division in PPK-expressing cells. Indeed, deletion of MSN2 and MSN4 in PPK-expressing strains improved growth in serial dilution assays (Fig. 3C), suggesting that these transcription factors hinder growth in the presence of non-vacuolar polyP. We next examined changes to Msn2 via western blotting. For these experiments, we developed an integrated GAL-inducible version of the PPK expression system (Fig. 3D). This allowed for better control over PPK expression and prevented strains from adapting to the presence of non-vacuolar polyP. The PPK construct contains an N-terminal HA epitope tag, which allowed us to monitor expression in mutant strains. Notably, GAL- 
induced HA-PPK expression resulted in growth defects in both $v t c 4 \Delta$ and WT strain backgrounds (Fig. 3D). We further validated our GAL-inducible system by demonstrating that Fet3-3FLAG is downregulated and Gcv1-3FLAG is upregulated following HA-PPK expression (Fig. 3E), mirroring what was observed for the plasmid-based expression system used in previous experiments. Loss of PKA dependent Msn2-NLS phosphorylation is associated with its nuclear localization and transcriptional activation of stress response element genes (Fig 3B ${ }^{[33]}$. HA-PPK-expressing cells had lower levels of this phosphorylated form of Msn2, which can be fortuitously detected using an antibody against human $\operatorname{pCREB}^{[33,34]}$ (Fig. 3F). Notably, total levels of total Msn2 were also reduced with PPK expression (Fig. 3F), an observation that may seem at odds with the idea of enhanced Msn2 activity. However, we note that nuclear Msn2 is thought to be destabilized during conditions of chronic stress and low PKA activity, as well as heat $\operatorname{shock}^{[32,35]}$.

Hog1 and Yak1 are upstream kinases that act on Msn2 to regulate its nuclear import, and at the promoter level to stimulate stress-dependent gene induction (Fig 3B $)^{[36,37]}$. Therefore, we next tested if Hog1 and Yak1 might be involved in the response to HA-PPK expression and polyP accumulation outside of the vacuole. While we saw no change in the expression of Hog1GFP or Yak1-GFP (Fig 4A and 4B), the electrophoretic mobility of Yak1-GFP was slightly but reproducibly increased with PPK expression (Fig. 4B). We surmised that this could represent a loss of autophosphorylation or PKA-dependent phosphorylation that accompanies Yak1 activation or translocation to the nucleus, respectively ${ }^{[38]}$. Indeed, PKA activity shows broad misregulation in PPK-expressing cells (Fig. 4C). Importantly, deletion of HOG1 or YAK1 partially

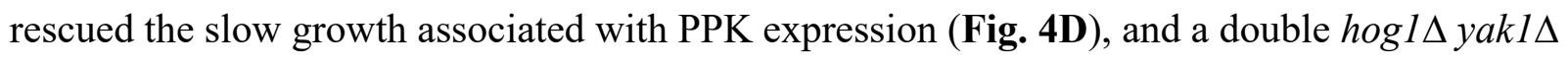
mutant had an even more dramatic effect (Fig. 4D). As a control, these strains had equal levels of 
HA-PPK expression (Supplementary Fig. 3). Collectively, our data suggest that Hog1 and Yak1 may signal through Msn2/Msn4 in response to polyP accumulation outside of the vacuole, and that activation of this signaling pathway inhibits growth.

\section{Ddp1 cooperates with Ppx1 to degrade non-vacuolar polyP:}

Since aberrant polyP outside of the vacuole leads to changes in expression of the proteome, we expect that mechanisms may exist to counter its accumulation. In yeast, work on polyphosphatase enzymes has focused on four proteins: Ppn1, Ppn2, Ppx1 and Ddp1. Ppn2 and Ddp1 are thought to act as endopolyphosphatases, which cleave polyP chains internally ${ }^{[2]}$. Ppx1 functions as an exopolyphosphatase that cleaves polyP chains starting at the end ${ }^{[2]}$. Ppn1 has been proposed to have both functions ${ }^{[2,39]}$. Work form the Mayer lab demonstrated that GALpr$P P X 1$ strains show decreased growth when grown in glucose (repressed $P P X 1$ ) versus galactose (PPX1 overexpression) in the presence of non-vacuolar poly $\mathrm{P}^{[4]}$. Whether $\mathrm{Ppx} 1$ works alone or in conjunction with additional polyphosphatases is unknown. Therefore, we tested the contribution of each of the four polyphosphatase enzymes in our system. Deletion of polyphosphatases PPN1 or PPN2 had no impact on the growth or viability of HA-PPK-expressing cells (Fig. 5A). This observation is consistent with their roles as vacuolar enzymes and the lack of impact of vacuolar polyP stores on PPK-induced toxicity (Fig 3D). In contrast, and as expected, $P P X 1$ deletion greatly enhanced the toxicity associated with PPK expression (Fig. 5B). Interestingly, a similar phenotype was observed in cells disrupted for $D D P 1$. In contrast to the slow growth phenotype conferred by PPK expression alone, deletion of these genes resulted in a dramatic decrease in viability in addition to slow growth (Fig. 5B). Interestingly, simultaneous deletion of $D D P 1$ and $P P X 1$ showed an effect that was not more dramatic than that observed in either single mutant 
(Fig. 5B). This largely epistatic relationship was recapitulated in the context of a liquid growth assay (Fig. 5C), suggesting that Ddp1 and Ppx1 function in the same pathway to counter the toxicity of polyP outside of the vacuole. Interpretation of these data is complicated somewhat by our observation that HA-PPK expression is lower in the double ppxld $d d p 1 \Delta$ relative to wildtype cells or either single mutant (Fig. 5G and Supplementary Fig. 4A). To test if Ddp1 and Ppx1 physically interact to degrade polyP in a concerted fashion, we attempted to coimmunoprecipitate 3HA-Ddp1 and Ppx1 but did not detect any interaction between the two proteins (Supplementary Fig. 4B).

To understand the mechanisms of Ppx1 and Ddp1 action, we analyzed polyP from our panel of polyphosphatase mutants. These experiments were conducted in a $v t c 4 \Delta$ background to allow visualization of HA-PPK-synthesized polyP rather than the VTC-synthesized polyP stored in the vacuole but released during the polyP isolation protocol. As we observed in the plasmidbased system, HA-PPK-synthesized polyP accumulated as predominantly long chains reminiscent of those synthesized by E. coli in response to cellular stress (Fig. 5D). Here again, the amount of polyP is far below that of a wild-type yeast cell, consistent with the notion that it is the localization of HA-PPK-synthesized polyP rather than the amount of that polyP that drives changes in cell growth ${ }^{[4]}$. HA-PPK-expressing strains lacking $P P X 1$ had more polyP, and the chains were of a medium length (Fig. 5D). Strains lacking DDP1 also showed increased polyP, but these chains were of the long form (Fig. 5D). The ppx $1 \Delta d d p 1 \Delta$ double mutant accumulated polyP chains of both medium and long lengths, with long chains being predominate. Overexpression of either enzyme reduced the level of PPK-synthesised polyP to background levels (Fig. 5D). While these experiments suggest that Ddp1 and Ppx1 act sequentially to 
degrade long chains of polyP, Ppx1 may also target a distinct population of medium-length chains synthesized by HA-PPK.

Yeast Ppx1 and Ddp1 show homology to human Prune and DIPP1-DIPP3, respectively ${ }^{[40,41]}$. Prune and DIPP1-DIPP3 have exo- or endopolyphosphatase activity in vitro ${ }^{[40-}$ ${ }^{42]}$. Only DIPP1 (also called NUDT3) has been described to have activity in vivo ${ }^{[42]}$. SamperMartin et al. show that DIPP1 overexpression confers a zinc-dependent reduction in polyP detected in HEK293T cells via a polyP binding probe ${ }^{[42]}$. Conversely, DIPP1 knockdown caused an increase in polyP in both HEK293T and SH-SY5Y cells using this same method of detection $^{[42]}$. To determine if candidate polyphosphatases could impact PPK-induced toxicity and/or polyP accumulation in yeast, we expressed them in yeast under the strong GPD promoter (Supplementary Fig. 5A). In contrast to DDPl overexpression, ectopic expression of human Prune or DIPP1-DIPP3 proteins did not improve growth in PPK-expressing cells (Fig. 5E) and did not decrease polyP accumulation (Fig. 5F). Since DIPP1 activity is thought to be zinc dependent $^{[42]}$, we added zinc to growth media used for these experiments. Although the highest concentrations of zinc used caused slight improvement of growth of strains expressing HA-PPK alone or in the presence of Prune, growth of DIPP1-DIPP3 expressing strains was unaffected (Supplementary Fig. 5B). Similarly, although the addition of zinc resulted in a slight decrease in polyP levels in all strains tested, this was not impacted by the ectopic expression of DIPP1 (Supplementary Fig 5C). Either Prune and DIPP1-DIPP3 do not directly impact the accumulation of long chain polyP in vivo, or their activities are not faithfully recapitulated in yeast under the conditions tested.

To corroborate and extend our findings with yeast Ppx1 and Ddp1, we analyzed lysine polyphosphorylation of previously identified targets ${ }^{[14]}$. Since lysine polyphosphorylation is a 
non-enzymatic modification, it is thought to be controlled largely by the concentration of polyP itself. We carried out these experiments in a $v t c 4 \Delta$ background to prevent interference of vacuolar polyP which can polyphosphorylate proteins during cell lysis ${ }^{[43]}$. Deletion of $P P X 1$ or DDP1 in PPK-expressing cells resulted in decreased electrophoretic mobility of polyphosphorylation targets Rts1 and Fpr3 on NuPAGE gels, indicative of lysine polyphosphorylation (Fig. 5G) ${ }^{[14]}$. Therefore, the 'extra' polyP in these cells is competent to participate in lysine polyphosphorylation reactions. The decreased electrophoretic mobility observed in ppx $1 \Delta$ and $d d p 1 \Delta$ cells could result from the modification of additional lysines at higher concentrations of poly $\mathrm{P}^{[44]}$. The greater impact of $d d p 1 \Delta$ may reflect the addition of longer chains to individual target lysines in these cells. We propose that the enhanced toxicity of PPK-expression observed in $d d p 1 \Delta$ and $p p x 1 \Delta$ mutants may be due in part to aberrant polyphosphorylation of proteins in the cytoplasm. 


\section{DISCUSSION:}

\section{Non-vacuolar polyP reprograms the yeast proteome:}

There are conflicting data concerning the concentration of polyP that accumulates outside of the vacuole in wild-type yeast, although it is generally accepted that the vacuole harbours substantially higher concentrations than other areas of the cell ${ }^{[2]}$. The sequestration of polyphosphate in specific subcompartments is not unique to yeast. Human cells accumulate high concentrations of polyP in the nucleolus or in dense granules of platelets ${ }^{[8,10]}$. Trypanosomes accumulate high levels of polyP in acidocalcisomes ${ }^{[45]}$, as well as glycosomes and the nucleolus in smaller amounts ${ }^{[46]}$. Even in many bacteria, polyP produced in response to stress is concentrated in granules $^{[2]}$. While the concentration of polyP in these areas is important for specific cellular functions (i.e. blood clotting in the case of dense granules ${ }^{[47]}$ ), it is less clear if polyP is actively excluded from (or limited within) some areas of the cell and why this might be important. Expression of bacterial PPK in yeast, coincident with production of polyP outside the vacuole, was previously demonstrated to reduce growth and sensitize cells to rapamycin and cycloheximide $^{[4,14]}$. Our new study provides a critical advance by $i$ ) identifying molecular pathways that mediate toxic effects of PPK expression, and ii) providing molecular insight into how exo- and endopolyphosphatases cooperate to counter the accumulation of non-vacuolar polyP in yeast.

We are not able to rule out that other enzymatic activities of the PPK enzyme (e.g. phosphorylation of nucleotides), contribute to the proteomic changes measured in our mass spectrometry experiments. However, the fact that PPK's impact is greatly exacerbated in strains lacking the Ddp1 and/or Ppx1 polyphosphatases, suggests that downstream changes in growth and/or viability are related to changes in polyP metabolism. PolyP could influence the expression 
or stability of some proteins directly, perhaps by binding to transcription factors or proteins themselves. We expect the investigation of such direct modes of action will provide clues to molecular functions of polyP that are broadly applicable, even under endogenous scenarios. Protein changes following PPK expression could also be indirect, for example, as a downstream result of polyP-mediated ion chelation or the cell's response to more direct activities.

Importantly, we consider such indirect effects to be equally interesting, as they provide valuable insights into how eukaryotic cells respond to mislocalized polyP and may aid in identification of scenarios when this occurs in the absence of PPK expression.

\section{Ddp1 and Ppx1 limit the toxic effects of non-vacuolar polyP:}

In ppx $1 \Delta$ and $d d p 1 \Delta$ ppx $1 \Delta$ cells expressing PPK, polyP accumulates as medium-length chains, similar to those made by the VTC complex in wild-type cells. This argues against the idea that PPK expression is toxic only because it makes long chains that are not normally seen in yeast. However, we can't rule out that different chain lengths have unique impacts on cell signaling and physiology and this remains an important area for future research. Indeed, there is precedent for chain-length dependent effects of polyP. For example, polyPs of different length affect different parts of the blood coagulation cascade ${ }^{[48]}$, and long chains preferentially stimulate changes in macrophage signaling important for the immune response ${ }^{[49]}$. Since we have not recovered any evidence of a physical interaction between Ddp1 and Ppx1, we propose that they act sequentially to degrade long polyP chains (Fig. 6), with Ddp1 first cleaving chains to generate free polyP 'ends' on which Ppx1 can then act. Notably, Ppx1 has also been shown to directly remove polyP chains from nuclear polyphosphorylated target $\mathrm{Nsr}^{[50]}$, and could act on other proteins in PPK-expressing cells to limit toxicity. 


\section{PolyP as an activator of stress signaling:}

We propose that polyP escaping degradation by polyphosphatases activates a stress-signaling pathway that limits cell growth or viability (Fig. 6). It is unclear if polyP is indeed causing some type of intracellular stress (i.e. accumulation of unfolded proteins), or if it is inappropriately activating stress-signaling pathways in the absence of a stress. Regardless, the downstream consequences appear to involve the PKA pathway, which plays a central role in the regulation of cell metabolism, growth, as well as diverse stress responses ${ }^{[51]}$. Our results show that accumulation of non-vacuolar polyP leads to broad misregulation of PKA substrates. Some of these substrates may include misregulated proteins identified in our mass spectrometry experiments. For example, Ura2, which is downregulated in PPK-expressing cells, is phosphorylated by PKA in vitro ${ }^{[52]}$. Moreover, PKA regulates the activity of Msn2/4 and Yak1 through direct phosphorylation ${ }^{[33,38]}$, and recently it has been suggested that PKA might modulate the activation of the Hog1 pathway during impaired sphingolipid biosynthesis ${ }^{[53]}$. Previous work has shown that deletion of $Y A K 1$ or MSN2 and MSN4 under conditions of low PKA activity rescues related slow-growth phenotypes ${ }^{[54,55]}$. We have shown that deletion of YAK1 or MSN2 and MSN4 also rescues growth in PPK-expressing cells, which is in accordance with scenarios of low PKA activity. Further, low PKA activity imparted by the accumulation of non-vacuolar polyP could explain the sensitivity of PPK-expressing cells to rapamycin ${ }^{[14]}$, since mutants with low PKA activity have increased sensitivity to this drug ${ }^{[56]}$. Our results suggest that non-vacuolar polyP might affect PKA activity directly or indirectly and that these changes may in part explain the observed toxicity (Fig. 6). 


\section{Endogenous functions of non-vacuolar polyP:}

Polyphosphate functions outside of the vacuole are poorly understood. The Ppx1 and Ppn1 polyphosphatases localize in part to the mitochondria and polyP here is suggested to play a role in energy homeostasis and metabolism ${ }^{[57]}$. Within the nucleus, polyphosphorylation may also inhibit the interaction of Top1 and Nsr1 proteins in addition to modulating their localization to the nucleolus ${ }^{[50]}$. It is also tempting to speculate that nuclear localization of polyphosphate underlies its poorly understood role in cell cycle regulation ${ }^{[58]}$. How polyP that functions in or transits through the cytoplasm in a wild-type cell avoids degradation by polyphosphatases is an intriguing question. It may be that these polyP molecules are bound by proteins or small molecules that prevent enzyme access to the phosphoanhydride bonds. It is also possible that Ddp1 and Ppx1 become activated to degrade cytoplasmic polyP only when the concentration exceeds a particular threshold. We further speculate that polyP could be released from vacuoles following damage with lysosomaltropic agents such as $N$-Dodecylimidazole ${ }^{[59]}$, or during sporulation, where the vacuole undergoes programed lysis ${ }^{[60]}$. Ddp1 and Ppx1 are ideally placed to regulating these responses.

\section{Regulation of polyP in human cells:}

We previously found that transient expression of PPK in human cells also resulted in polyP accumulation throughout the cell ${ }^{[61]}$. Accumulation of long-chain polyP was associated with broad changes in gene and protein expression, increased phosphorylation of ERK1/2 and p70S6K, and redistribution of multiple nuclear proteins from the nucleus/cytoskeletal fraction to the cytoplasm and/or organelles ${ }^{[61]}$. We did not observe activation of apoptotic pathways or signs of extensive cell death ${ }^{[61]}$, consistent with a previous report ${ }^{[62]}$. However, it is possible that in the context of our transient expression system, plasmid copy number, PPK expression, and/or polyP 
itself are quickly downregulated to manageable levels. Based on our work in yeast, we expect that inhibition of polyphosphatases will increase levels of polyP to levels that confer greater toxicity. Our study further suggests that degradation of long-chain polyP in human cells will require the combined action of both endo- and exopolyphosphatases, akin to what we observed for Ddp1 and Ppx1. Mammalian polyphosphatases may also play a role in degrading long-chain polyP made by pathogenic bacteria, which has been suggested to enter cells during infection to reprogram macrophages and thereby subvert host defense mechanisms ${ }^{[49]}$. The identities of intracellular human polyphosphatases had long remained unknown, but Prune and DIPP1-DIPP3 have emerged as candidates based on their in vitro activities ${ }^{[40,41,63]}$. Notably, mutations that reduce Prune activity in vitro give rise to the rare disease called Neurodevelopmental disorder with microcephaly, hypotonia and variable brain anomalies (NMIHBA) ${ }^{[63]}$. However, expressing either Prune or DIPP1-DIPP3 in yeast resulted in no appreciable change in viability and no obvious decrease in PPK-synthesized polyP. We note that the in vitro exopolyphosphatase activity of Prune is mostly against very short chains (3-4 phosphate units in length $)^{[41,63]}$. In our experiments, Prune was also expressed at substantially lower levels than the DIPP1-DIPP3 proteins in yeast, despite the fact that both constructs used the GPD promoter. Together, these observations could account for the lack of effect observed in our system. More surprising is the observation that expression of DIPP1 had no effect in either the presence or absence of zinc. This finding is seemingly at odds with the exciting work of Samper-Martin et al., which describes a zinc-dependent activity of DIPP1 (also called NUDT3) in HEK293 and SH-S5Y cells ${ }^{[42]}$. One exciting possibility is that DIPP1 or other mammalian polyphosphatase enzymes require additional co-factors besides zinc that are not normally present in yeast. Such proteins could 
bioRxiv preprint doi: https://doi.org/10.1101/2022.02.02.478728; this version posted February 2, 2022. The copyright holder for this preprint (which was not certified by peer review) is the author/funder, who has granted bioRxiv a license to display the preprint in perpetuity. It is made available under aCC-BY-NC 4.0 International license.

serve as important regulators of in vivo polyphosphatase activity and should be a focus of future work. 


\section{MATERIALS \& METHODS:}

Yeast strains \& handling: Yeast strains were constructed as previously described using standard methods ${ }^{[64-66]}$. Locations of gene deletion and tagging cassettes were confirmed using PCR analyses ${ }^{[66]}$. Full genotypes of all yeast strains used in this work are listed in Supplementary Table S2. Cells were grown in YPD, YEP-Raf. YEP-Gal, or synthetic complete media as described below for individual experiments. In general, SC-Ura and SC-Leu media were used to maintain $U R A 3$-based and LEU2-based selection plasmids, respectively.

Plasmids: All plasmids used for this work are listed in Supplementary Table S5. All plasmids generated for this work will be made available from Addgene (www.Addgene.org) following publication.

Proteomics: The mass spectrometry proteomics data have been deposited to the ProteomeXchange Consortium via the PRIDE (PMID: 34723319) partner repository with the dataset identifier PXD031326. Reviewers can access the data in PRIDE using the following username: reviewer_pxd031326@ebi.ac.uk and password: oZF6dkud. Summary data is provided in Supplementary Table S1.

\section{Polyphosphate extractions:}

Cell growth: Cells expressing indicated plasmids in Fig. 1A and Fig. 2C were diluted to OD600 $=0.2$ in SC-Ura $+2 \%$ glucose and grown at $30{ }^{\circ} \mathrm{C}$ with shaking until the OD600 reading reached a final value of $0.8-1$. Cells in Fig. 5D were diluted to OD600 $=0.2$ in YEP $+2 \%$ raffinose and grown for 3 hours before adding $2 \%$ galactose and growing another 3 hours. Cells 
expressing indicated plasmids in Fig. 5F were diluted to OD600 $=0.2$ in SC-Ura $+2 \%$ raffinose and grown for 3 hours before adding $2 \%$ galactose and growing another 3 hours.

PolyP extraction: The polyP isolation protocol was adapted from a protocol first described by Bru et al. $2017^{[67]}$ and described elsewhere ${ }^{[61]}$. The protocol is repeated here using similar language. Yeast cell pellets of approximately 8 OD600 units in size were resuspended in $400 \mu \mathrm{L}$ of cold LETS buffer (100 mM LiCl, 10 mM EDTA, 10 mM Tris-HCl pH 7.4, 0.2 \% SDS), transferred to a screw cap tube containing $600 \mu \mathrm{L}$ of phenol $\mathrm{pH}=8$ and $150 \mu \mathrm{L}$ of $\mathrm{mqH}_{2} 0$, and vortexed for $20 \mathrm{sec}$. Samples were then heated for $5 \mathrm{~min}$ at $65^{\circ} \mathrm{C}$ and cooled on ice for 1 minute. Once cooled, $600 \mu \mathrm{L}$ of chloroform was added and the samples were vortexed for 20 seconds. Vortexed samples were centrifuged for $2 \mathrm{~min}$ at $13000 \mathrm{x} \mathrm{g}$ at room-temperature and the top layer was transferred to a new tube containing $600 \mu \mathrm{L}$ of chloroform. Samples were vortexed and centrifuged again for $2 \mathrm{~min}$ at $13000 \mathrm{x} \mathrm{g}$, and the top layer was transferred to a clean $1.5 \mathrm{~mL}$ tube. To degrade RNA and DNA, $2 \mu \mathrm{L}$ of $10 \mathrm{mg} / \mathrm{mL}$ RNAse A and $2 \mu \mathrm{L}$ of $10 \mathrm{mg} / \mathrm{mL}$ DNAse I were added to samples and incubated at $37^{\circ} \mathrm{C}$ for 1 hour. Digested samples were transferred to pre-chilled $1.5 \mathrm{ml}$ tubes containing $1 \mathrm{ml}$ of $100 \%$ ethanol and $40 \mu \mathrm{l}$ of $3 \mathrm{M}$ sodium acetate $\mathrm{pH}=$ 5.3 and polyP was left to precipitate at $-20^{\circ} \mathrm{C}$ for at least 3 hours or overnight. PolyP was pelleted by centrifugation for $20 \mathrm{~min}$ at $13000 \mathrm{x}$ g at $4{ }^{\circ} \mathrm{C}$ and the supernatant was discarded. The pellet was washed with $500 \mu \mathrm{L}$ of $70 \%$ ethanol and centrifuged for an additional $5 \mathrm{~min}$. The supernatant was discarded and the pellets were air dried before being resuspended in $20-30 \mu \mathrm{L}$ of $\mathrm{mqH}_{2}$. Gel analysis: Extracted polyP was diluted 1:1 with polyP loading buffer (10 mM Tris$\mathrm{HCl} \mathrm{pH}$ 7, $1 \mathrm{mM}$ EDTA, $30 \%$ glycerol, bromophenol blue) and $15 \mu \mathrm{L}$ was loaded on a $15.8 \%$ TBE-Urea gel (5.25 g Urea, 7.9 mL $30 \%$ acrylamide, 3 mL 5 X TBE, $150 \mu \mathrm{L} 10 \%$ APS, $15 \mu \mathrm{L}$ TEMED) and run at $100 \mathrm{~V}$ for $1 \mathrm{~h} 45 \mathrm{~min}$ in $1 \mathrm{X}$ TBE running buffer. For toluidine blue staining, 
the gel was incubated in fixing solution with toluidine blue (25\% methanol, $5 \%$ glycerol, 0.05 $\%$ toluidine blue) for $20 \mathrm{~min}$ and destained with fixative solution without toluidine blue. For DAPI staining, the protocol was adapted from Smith and Morrisey $2007^{[68]}$. Extracted polyP was diluted $1: 60$ for wild-type strains and $1: 10$ for $v t c 4 \Delta$ with polyP loading buffer and $15 \mu \mathrm{L}$ was loaded. The gel was incubated in fixing solution with DAPI (25\% methanol, $5 \%$ glycerol, 50 $\mathrm{mM}$ tris base, $2 \mathrm{ug} / \mathrm{mL}$ DAPI) for 30 minutes. The gel was destained with fixative solution without DAPI for 1 hour, changing solution once halfway through. The destained gel was exposed to $365 \mathrm{nM} \mathrm{UV} \mathrm{light} \mathrm{on} \mathrm{a} \mathrm{transilluminator} \mathrm{to} \mathrm{photobleach} \mathrm{the} \mathrm{DAPI-polyP} \mathrm{until} \mathrm{it}$ became dark. Pictures were taken with a Bio-Rad ChemiDoc UV transilluminator.

\section{Label-free mass spectrometry:}

Sample preparation: Sample preparation and mass spectrometry protocols are based on an experimental set up we have used previously for work in HEK293T cells ${ }^{[61]}$. Similar language is used in the description here. Cells were diluted to OD600 $=0.2$ in SC-Ura with $2 \%$ glucose and grown at $30{ }^{\circ} \mathrm{C}$ with shaking until OD600 $=1$. Yeast pellets of approximately 50 OD600 units in size were resuspended in $600 \mu \mathrm{L}$ of lysis buffer (5\% SDS, 50mM TEAB, supplemented with protease and phosphatase inhibitor tablets (Roche)) and the $2 \mathrm{~mL}$ screwcap tube was filled to capacity with acid-washed glass beads. Cells were lysed with 12 x 1 minute pulses on a BioSpec mini bead-beater with incubation on ice in between pulses. Lysates were clarified by centrifugation at $15000 \mathrm{xg}$ for $10 \mathrm{~min}$ at $4{ }^{\circ} \mathrm{C}$. The supernatant was collected and centrifuged again at $15000 \mathrm{x}$ g for $10 \mathrm{~min}$ at $4{ }^{\circ} \mathrm{C}$ before being collected again and frozen at $-80{ }^{\circ} \mathrm{C}$. Frozen protein extracts were shipped overnight on dry ice to the UC Davis Proteomics core. Trypsin 
digestion was performed using S-Trap Mini spin columns (PROTIFI) as per the manufacturer's protocol.

Liquid chromatography and mass spectrometry analysis: Digested peptides were first separated using Proxeon Easy-nLC II HPLC (Thermo Scientific) and Proxeon nanospray source. Digested peptides were loaded on a 100 micron x 25 mm Magic C18 $100 \AA$ 5U reverse phase trap where they were desalted on-line before being separated using a 75 micron x 150 mm Magic C18 $200 \AA$ 3U reverse phase column. Peptides were eluted using a 140 minute gradient with a flow rate of 300 nl/min into a Thermo Scientific Q Exactive Plus Orbitrap mass spectrometer. An MS survey scan was obtained for the $\mathrm{m} / \mathrm{z}$ range of $350-1600$. MS/MS spectra were acquired with the top 15 ions in the MS spectra subjected to Higher Energy Collisional Dissociation, with a resolution at $400 \mathrm{~m} / \mathrm{z}$ of 70,000 and 17,500 at the MS1 and MS2 levels, respectively. For precursor ion selection, an isolation mass window of $1.6 \mathrm{~m} / \mathrm{z}$ was used. A normalized collision energy of $27 \%$ was used for fragmentation. Dynamic exclusion was set for fifteen seconds.

Bioinformatics analyses: For mass spectrometry data, the bioinformatics pipeline used for analysis is similar to that previously described ${ }^{[61]}$. The details are presented here with minimal rewording for clarity.

\section{Protein identification:}

Tandem mass spectra were extracted using the msConvert program ${ }^{[69]}$. X!Tandem (the gmp.org; version X! Tandem ALANINE (2017.2.1.4)) was used to analyze MS/MS spectra and identify peptide sequences $^{[70]}$. The X!Tandem program was used to search the SwissProt Uniprot $S$. cerevisiae database $^{[71]}$ (proteome UP000002311, date of download = 2018-12-21), along with 
110 common lab contaminants (thegpm.org/crap/) and the E. coli PPK protein sequence, and all of these sequences reversed for a decoy database search. A database search was performed on MS/MS spectra from precursor ions with a charge state of at most 4 . Trypsin was set as the digestion enzyme. Using X!Tandem two-pass search, the initial search was performed with one miscleavage considered, and a refinement search looked for additional unanticipated miscleavages in peptides from proteins identified in the first pass. Fragment ion and parent ion mass tolerances were set to $20 \mathrm{ppm}$. Single amino acid polymorphisms were checked for each peptide residue in the first search, using a default list of polymorphisms from the SNP annotations in ENSEMBL ${ }^{[72]}$. Carbamidomethylation of cysteine and selenocysteine were specified as fixed modifications. Variable modifications included were: glutamic acid->pyroglutamic acid of the N-terminus, glutamine->pyro-glutamine of the N-terminus, ammonia loss of the N-terminus, deamidation of asparagine and glutamine, oxidation and dioxidation of both methionine and tryptophan, and N-terminal acetylation. Validation of peptide and protein identifications was done using the Scaffold program (version 4.11.1 from Proteome Software, Inc, Portland OR). The ProteinProphet algorithm was used to assign protein identification probabilities. Peptide identifications associated with an FDR $<1 \%$ were deemed of high confidence. Protein identifications with an FDR $<1 \%$ and associated with at least 2 highconfidence peptides were then used in all downstream analyses. Proteins were grouped into protein groups if they shared significant peptide evidence. To satisfy the principles of parsimony, proteins sharing the same peptides were grouped if it was not possible to differentiate them based on MS/MS analyses. 


\section{Differential protein expression analysis}

Protein and protein group spectral counts were retrieved from Scaffold. To account for missing values, spectral counts were imputed for all spectral count values equal to zero by randomly sampling spectral count values from the bottom $20 \%$ of non-zero spectral counts. Spectral counts were normalized by the total number of spectral counts in each MS/MS runs. Protein differential expression was assessed using a two-tailed, two-sample Student's $t$-test assuming unequal variance on normalized spectral counts. Differential expression was assessed using a $t$ test only for proteins that were reproducibly identified in 3 or more replicates in both experimental conditions. The Benjamini-Hochberg procedure ${ }^{[73]}$ was used to correct for multiple hypothesis testing. Proteins were deemed differentially expressed when their FDR-adjusted $p$ value was smaller or equal to 0.1 . In addition, proteins with extreme expression differences (i.e. detected in all replicates in one condition and in none for the other condition) are also reported and named "all-or-none" proteins.

\section{Gene Ontology enrichment analysis}

In order to investigate key functional changes in response to ectopic expression of PPK1, a Gene Ontology ${ }^{[74]}$ enrichment analysis was performed using Ontologizer ${ }^{[75]}$. Differentially expressed proteins (FDR-adjusted $p$-value $\leq 0.1)$ and all-or-none proteins were evaluated for enrichment against a background of all identified proteins in all MS/MS runs (FDR $<1 \%)$. The OBO ontology file and GAF annotation file used for gene ontology enrichment analysis were downloaded from http://geneontology.org/ on 2019-08-22 and 2020-01-20, respectively. The $p$ values were adjusted using the Benjamini-Hochberg procedure to correct for multiple hypothesis testing. 


\section{Protein-protein interaction network}

The STRING ${ }^{[21]}$ database was used to construct a protein-protein interaction network between differentially expressed proteins (FDR-adjusted $p$-value $\leq 0.1$ ) and all-or-none proteins. The network was constructed using the STRING medium confidence (0.4) threshold for experimental evidence and database evidence of interactions. Proteins without any protein-protein interactions were removed from the network.

YEASTRACT analysis: Genes of differentially expressed proteins (FDR-adjusted $p$-value $\leq$ 0.1) and all-or-none proteins were ranked by transcription factor using YEASTRACT (http://www.yeastract.com/formrankbytf.php $)^{[28]}$. Documented regulations were filtered by DNA binding or expression evidence, transcription factor acting as activator or inhibitor, and all transcription factors were checked.

Immunoprecipitation: Cells were diluted to OD600 $=0.2$ in YEP $+2 \%$ raffinose and grown for 3 hours before inducing 3HA-Ddp1 expression with $2 \%$ galactose for 2 hours. Yeast cell pellets of approximately 50 OD600 units were resuspended in $750 \mu \mathrm{L}$ of lysis buffer $(0.1 \%$ NP40, $150 \mathrm{mM} \mathrm{NaCl}, 50 \mathrm{mM}$ Tris-HCl pH 8, $10 \%$ glycerol, $15 \mathrm{~mL}$ of buffer was supplemented with $30 \mu \mathrm{L}$ of $1 \mathrm{M}$ imidazole, $15 \mu \mathrm{L}$ of $1 \mathrm{M}$ sodium fluoride, $17.25 \mu \mathrm{L}$ of $1 \mathrm{M}$ sodiummolybdate, $75 \mu \mathrm{L}$ of $200 \mathrm{mM}$ sodium orthovanadate, $75 \mu \mathrm{L}$ of $1 \mathrm{M} \mathrm{DTT}, 15 \mu \mathrm{L} 5 \mathrm{mM}$

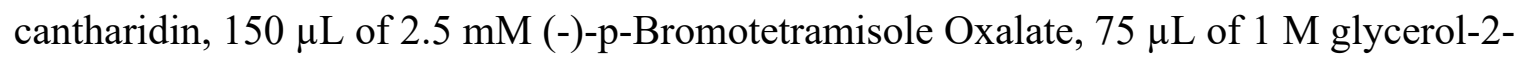
phosphate, $15 \mu \mathrm{L}$ of $0.1 \mathrm{M}$ PMSF, and a $15 \mathrm{~mL}$ Roche cOmplete protease inhibitor tablet with EDTA $^{[14,50]}$, and the $2 \mathrm{~mL}$ screwcap tubes were filled to capacity with acid-washed glass beads. Cells were lysed with $8 \times 1.5$ minute pulses on a BioSpec mini bead-beater with incubation on ice in between pulses. Lysates were clarified by centrifugation at $15000 \mathrm{x}$ for $10 \mathrm{~min}$ at $4{ }^{\circ} \mathrm{C}$. 
The supernatant was collected and centrifuged again at $15000 \mathrm{xg}$ for $10 \mathrm{~min}$ at $4{ }^{\circ} \mathrm{C}$. Anti-HA antibody was added to each lysate at a dilution of 1/650 and rotated end over end for 1 hour at 4 ${ }^{\circ} \mathrm{C}$. After incubating, $20 \mu \mathrm{L}$ of Protein A Magnetic Beads were washed 3 times with $700 \mu \mathrm{L}$ of lysis buffer and were added to each sample and rotated end over end for 1 hour at $4{ }^{\circ} \mathrm{C}$. Samples were centrifuged briefly to pellet beads and lysate was removed. Beads were washed 3 times with $700 \mu \mathrm{L}$ of lysis buffer and eluted with sample buffer by boiling for 10 minutes.

Immunoblotting: Proteins were extracted using a method that was described previously ${ }^{[14]}$. That method is described again here for convenience. Cell pellets of OD600 $=3-6$ units (as measured using an Eppendorf BioPhotometer) were resuspended in $300 \mu \mathrm{L}$ of $20 \%$ TCA and $100 \mu \mathrm{L}$ of acid-washed glass beads. Cells were lysed with 2 x 3 minute pulses on a BioSpec mini beadbeater. Supernatant was removed and kept. Beads were washed with $300 \mu \mathrm{L} 5 \%$ TCA and this supernatant was combined with the first $300 \mu \mathrm{L}$. This mixture was clarified via centrifugation for 4 minutes at $4{ }^{\circ} \mathrm{C}$ at $16000 \mathrm{x}$. The resulting pellet was dissolved in $100 \mu \mathrm{L}$ of SDS-PAGE loading buffer supplemented with $1 / 10$ volume $1.5 \mathrm{M}$ Tris- $\mathrm{HCl} \mathrm{pH} 8.8$ and $1 / 10$ volume $1 \mathrm{M}$ DTT and boiled for 8 minutes. Samples were centrifuged again at $16000 \mathrm{x} \mathrm{g}$ and the supernatant was recovered. Approximately 10-20 $\mu \mathrm{L}$ were loaded per gel (corresponding to about $75 \mu \mathrm{g}$ of protein). Unless stated otherwise in figure legends, protein samples were run on $10 \%$ SDSPAGE gels made from a $30 \%$ acrylamide/bis solution, $37.5: 1$. To resolve polyphosphorylation induced shifts, protein samples were run on NuPAGE 4 to $12 \%$ Bis-Tris gels. Buffers used for both gel types were described previously ${ }^{[14]}$. All proteins were transferred to PVDF membranes before probing with antibodies. The antibodies used for this work are detailed in Supplementary

\section{Table S4.}


Spot tests: Cells from freshly grown plates were diluted in water and spotted on the indicated media and allowed to dry prior to incubation at $30^{\circ} \mathrm{C}$ for $2-3$ days.

Liquid growth curves: Overnight cultures grown in YEP with $2 \%$ raffinose were diluted to OD600 $=0.2$ in YEP with $2 \%$ raffinose and incubated at $30{ }^{\circ} \mathrm{C}$ with shaking for 4.5 hours $(\mathrm{OD} 600=0.6-0.8)$. Cultures were subsequently diluted to OD600 $=0.1$ (measured using an Eppendorf BioPhotometer) in YEP with $2 \%$ raffinose or YEP with $2 \%$ galactose. $200 \mu \mathrm{L}$ of cells were pipetted into wells of a 100 well honeycomb plate and the plate was incubated in a Bioscreen C plate reader (Oy Growth Curves) set at $30{ }^{\circ} \mathrm{C}$ with continuous shaking. A wavelength of $600 \mathrm{~nm}$ was used to measure optical density every 15 minutes for 24 hours. 


\section{CONFLICTS OF INTERESTS:}

The authors declare no conflicts.

\section{ACKNOWLEDGEMENTS:}

We thank Dr. T. Shiba (RegeneTiss, Japan) for the gift of polyP standards and Andreas Mayer for the original p416-GPD and p416-GPD-PPK plasmid. We thank the UC Davis Proteomics Core Facility for mass spectrometry analysis. We also thank the Rudner Lab for the Cdc55 antibody, as well as the Baetz Lab for the Msn2 and p-PKA substrate antibodies. Work for this project was funded by Canadian Institutes of Health Research (CIHR) Project Grants to MD (PJT-148722) and MD \& MLA (PJT- 450860) and a Natural Sciences and Engineering Research Council of Canada (NSERC) Discovery Grant to MLA. Trainees in the Downey Lab are supported in part by an Early Researcher Award from the Ontario Ministry of Research, Innovation and Science. LM was supported by an Ontario Graduate Scholarship and a NSERC Canada Graduate Scholarship. IA was supported by an Ontario Graduate Scholarship and a NSERC Canada Graduate Scholarship. 


\section{FIGURE LEGENDS:}

Figure 1 - The proteome of PPK-expressing yeast. A) PPK expression in yeast allows for production of polyP outside of the vacuole. Polyphosphate was extracted from the strains expressing the indicated constructs and visualized using DAPI staining following separation on $15.8 \%$ acrylamide TBE-Urea gel. B) Workflow for data dependent-based label-free mass spectrometry analysis. C) Volcano plot with proteins up- or downregulated following PPK expression in a $v t c 4 \Delta$ background. Red proteins are downregulated (adjusted $p$-value $<0.05$ ), blue proteins are upregulated (adjusted $p$-value $<0.05$ ). Black proteins are those with adjusted $p$ value $\leq 0.1$. D) Table of top mis-regulated proteins identified with an adjusted $p$-value $<0.05$. Images representative of $\mathrm{n} \geq 3$ experiments. Also see Supplementary Figure 1.

\section{Figure 2 - The response to PPK expression is not impacted by the presence of vacuolar}

polyP. A)-B) Protein extracts from the indicated strains were prepared using a TCA-lysis protocol and separated on SDS-PAGE gels. Separated proteins were transferred to PVDF membrane prior to probing with anti-FLAG antibody to detect candidate proteins. Ponceau S stain of the PVDF membrane is shown as a loading control. C) Polyphosphate was extracted from the strains expressing the indicated constructs and visualized using toluidine blue staining following separation on a $15.8 \%$ acrylamide TBE-Urea gel. The asterisk indicates non-specific staining of an unknown product that is not polyP. D) 10-fold dilutions of the indicated strains were spotted on SC-Ura and incubated for 48 hours at $30{ }^{\circ} \mathrm{C}$. E) Protein extracts from the indicated strains were analyzed as described in (A). F) STRING analysis locates mis-regulated proteins in sub-networks of physically interacting proteins. Line colours: magenta: experimental 
evidence, cyan: database evidence, purple: database evidence (specifically protein homology). Images representative of $\mathrm{n} \geq 3$ experiments. Also see Supplementary Figure 2.

Figure 3 - Msn2 and Msn4 transcription factors limit viability in PPK-expressing cells. A) YEASTRACT analysis was used to identify candidate transcriptional regulators based on proteins up- and downregulated in mass spectrometry analysis See Materials and Methods for details. The $\%$ numbers show the fraction of misregulated proteins (adjusted $p$-value $\leq 0.1$ ) whose encoding genes are regulated by the indicated transcription factors. B) Relationship between Yak1/Hog1 and Msn2/4 in stress signaling. C) 10-fold serial dilutions of the indicated strains transformed with empty or PPK-expressing vector were spotted on the indicated media and incubated for 48 hours at $30{ }^{\circ} \mathrm{C}$. D) Schematic of an inducible HA-PPK expression system under control of the GAL-promoter. GAL-induced HA-PPK expression results in decreased growth in both $v t c 4 \Delta$ and wild-type background. 10-fold serial dilutions of the indicated strains were spotted on the indicated media and incubated for 72 hours at $30{ }^{\circ} \mathrm{C}$. E) Protein extracts from the indicated strains harbouring the inducible HA-PPK expression system were prepared using a TCA-lysis protocol and separated on SDS-PAGE gels. Separated proteins were transferred to PVDF membrane prior to detection of proteins with the indicated antibodies. Ponceau S stain of the PVDF membranes is shown as loading controls. F) Protein extracts from the indicated strains were prepared and analyzed as described in (E). A phospho-CREB antibody was used to detect the NLS specific phosphorylation of Msn2. Cdc55 is used as a loading control. Images representative of $n \geq 3$ experiments.

Figure 4 - Yak1 and Hog1 kinases modulate the response to PPK-expression 
A) Hog1-GFP levels are unaffected by PPK expression. Protein extracts from the indicated strains were prepared using a TCA-lysis protocol and separated on SDS-PAGE. Separated proteins were transferred to PVDF membrane before probing with indicated antibodies to detect proteins of interest. Ponceau S stain of the PVDF membrane is shown as a loading control. B) PPK expression leads to an increase in the electromobility of Yak1. Protein extracts from the indicated strains were prepared and analyzed as described in (A), but proteins were run on a 10 \% SDS-PAGE gel with a $77: 1$ acrylamide to bis ratio. C) Phosphorylated PKA substrates were detected using an antibody that detects phosphorylated serine or threonine residues with arginine at the -3 and -2 positions (RRXS*/T*). Blue arrows indicate upregulated phosphorylated PKA substrates and yellow arrows indicate downregulated substrates. Ponceau S stain of the PVDF membrane is shown as a loading control. D) 10 -fold serial dilutions of the indicated strains were spotted on the indicated media and incubated for 72 hours at $30{ }^{\circ} \mathrm{C}$. Images representative of $\mathrm{n} \geq$ 3 experiments. Also see Supplementary Figure 3.

Figure 5 - PolyP accumulation outside of the vacuole is countered by Ppx1 and Ddp1. A-B) The indicated strains were spotted in a 5 -fold dilution series on plates containing $2 \%$ glucose or $1.8 \%$ raffinose $+0.2 \%$ galactose and incubated at $30{ }^{\circ} \mathrm{C}$ for 72 hours. C) Growth curves for the indicated strains were generated using the Bioscreen $\mathrm{C}$ system described in the materials and methods. D) Polyphosphate was extracted from the indicated strains and visualized using toluidine blue staining following separation on a $15.8 \%$ acrylamide TBE-Urea gel. The asterisk indicates non-specific staining of an unknown product that is not polyP. E) Strains with the indicated plasmids expressing yeast or candidate human polyphosphatase enzymes were spotted in 10-fold dilution series and incubated at $30{ }^{\circ} \mathrm{C}$ for 72 hours. F) Polyphosphate was extracted 
from the strains expressing the indicated plasmids and analyzed as in (D). G) After a 1 hour galactose induction of HA-PPK, lysine polyphosphorylation of Fpr3 and Rts1 was analyzed by NuPAGE followed by transfer to PVDF membrane and detection of proteins using the indicated antibodies. Ponceau S stain of the membrane is used as a loading control. Images representative of $n \geq 3$ experiments. Also see Supplementary Figures 4 and 5.

Figure 6 - Working model for the cellular response to non-vacuolar polyP in yeast. PPKproduced polyP accumulates in the cytoplasm and slows growth by a variety of pathways which include activation a Yak1/Hog1-Msn2/4 signaling cascade. The accumulation of polyP outside of the vacuole is countered by Ppx1 and Ddp1 which work together to degrade polyP. See text for details.

\section{Supplementary Figure 1 - Changes to the $S$. cerevisiae proteome with ectopic PPK}

expression. PPK expression restores polyphosphate levels in samples used for mass

spectrometry. Protein extracts were prepared from the indicated strains carrying either control or PPK expressing plasmids using an SDS lysis protocol and separated on a NuPAGE gel.

Separated proteins were transferred to PVDF before probing with an antibody that recognizes

yeast Fpr3. Ponceau S stain of the membrane is shown as a loading control. The shift observed in PPK-expressing samples is a sign of lysine polyphosphorylation and polyP production.

\section{Supplementary Figure 2 - Supplementing media with excess metals does not rescue PPK-}

induced growth defects. The indicated strains were spotted in 10-fold dilution series on media 
containing $200 \mu \mathrm{M}$ of the indicated metals and incubated at $30{ }^{\circ} \mathrm{C}$ for 48 hours. Images representative of $n=2$ experiments.

Supplementary Figure 3 - HA-PPK levels in the HOG1 and $Y A K 1$ mutants. Protein extracts from the indicated strains were prepared using a TCA-lysis protocol and separated on SDSPAGE. Separated proteins were transferred to PVDF and probed with anti-HA to detect HAPPK. Ponceaus S stain is shown as a loading control. Images representative of $n=3$ experiments.

\section{Supplementary Figure 4 - HA-PPK regulation in polyphosphatase mutants. A) PPK levels}

in polyphosphatase mutants. Protein extracts from the indicated strains were prepared using a TCA-lysis protocol and separated on SDS-PAGE. Separated proteins were transferred to PVDF and probed with anti-HA to detects HA-PPK. Ponceau S is shown as a loading control. B) Ppx1 does not co-immunoprecipitate with Ddp1. 3HA-Ddp1 was immunoprecipitated using an antiHA antibody and then recovered using protein A agarose beads before elution in sample buffer. Eluted proteins from indicated strains were separated on SDS-PAGE and transferred to PVDF membrane prior to probing with anti-HA to detect 3HA-Ddp1 and anti-Ppx1 to detect Ppx1. Images representative of $n=3$ experiments for $(A)$ and $n=2$ for (B).

\section{Supplementary Figure 5 - Overexpression of potential mammalian polyphosphatases. A)}

Protein extracts from the indicated strains were analyzed using a $12 \%$ SDS-PAGE gel following a TCA-style lysis, prior to transfer to PVDF membrane and detection with anti-HA to detect HAPPK. Strains are transformed with empty vector, HA-tagged PRUNE, HA-tagged DIPP1, HAtagged DIPP2, HA-tagged DIPP3A, HA-tagged DIPP3B, or yeast Ddp1 expressing plasmids. 
Ponceau S stain is shown as a loading control. B) Strains with the indicated plasmids expressing potential mammalian polyphosphatases or yeast Ddp1 were spotted in 10-fold serial dilutions on indicated media supplemented with or without zinc sulfate. C) Polyphosphate was extracted from strains expressing the indicated plasmids and visualized using toluidine blue staining following separation on a $15.8 \%$ acrylamide TBE-Urea gel. The asterisk indicates non-specific staining of an unknown product that is not polyP. Images representative of $n=3$ experiments. 


\section{SUPPLEMENTARY TABLES:}

Supplementary Table S1 - Mass spectrometry data (.xlsx)

Supplementary Table S2 - Summary of MS dataset confirmations (.xlsx)

Supplementary Table S3 - Yeast strains used in this work (.xlsx)

Supplementary Table S4 - Antibodies used in this work (.xlsx)

Supplementary Table S5 - Plasmids used in this work (.xlsx) 


\section{REFERENCES:}

[1] Hothorn, M., Neumann, H., Lenherr, E. D., Wehner, M., Rybin, V., Hassa, P. O., .. . Mayer, A. (2009). Catalytic core of a membrane-associated eukaryotic polyphosphate polymerase. Science, 324(5926), 513-516. doi: 10.1126/science.1168120

[2] Denoncourt, A., \& Downey, M. (2021). Model systems for studying polyphosphate biology: a focus on microorganisms. Curr Genet, 67(3), 331-346. doi: 10.1007/s00294-02001148-X

[3] Desfougeres, Y., Gerasimaite, R. U., Jessen, H. J., \& Mayer, A. (2016). Vtc5, a Novel Subunit of the Vacuolar Transporter Chaperone Complex, Regulates Polyphosphate Synthesis and Phosphate Homeostasis in Yeast. J Biol Chem, 291(42), 22262-22275. doi: 10.1074/jbc.M116.746784

[4] Gerasimaite, R., Sharma, S., Desfougeres, Y., Schmidt, A., \& Mayer, A. (2014). Coupled synthesis and translocation restrains polyphosphate to acidocalcisome-like vacuoles and prevents its toxicity. J Cell Sci, 127(Pt 23), 5093-5104. doi: 10.1242/jcs. 159772

[5] Kornberg, A., Rao, N. N., \& Ault-Riche, D. (1999). Inorganic polyphosphate: a molecule of many functions. Annu Rev Biochem, 68, 89-125. doi: 10.1146/annurev.biochem.68.1.89

[6] Uttenweiler, A., Schwarz, H., Neumann, H., \& Mayer, A. (2007). The vacuolar transporter chaperone (VTC) complex is required for microautophagy. Mol Biol Cell, 18(1), 166175. doi: 10.1091/mbc.e06-08-0664

[7] Baijal, K., \& Downey, M. (2021). The promises of lysine polyphosphorylation as a regulatory modification in mammals are tempered by conceptual and technical challenges. Bioessays, e2100058. doi: 10.1002/bies.202100058

[8] Jimenez-Nunez, M. D., Moreno-Sanchez, D., Hernandez-Ruiz, L., Benitez-Rondan, A., Ramos-Amaya, A., Rodriguez-Bayona, B., . . Ruiz, F. A. (2012). Myeloma cells contain high levels of inorganic polyphosphate which is associated with nucleolar transcription. Haematologica, 97(8), 1264-1271. doi: 10.3324/haematol.2011.051409

[9] Xie, L., Rajpurkar, A., Quarles, E., Taube, N., Rai, A. S., Erba, J., . . Knoefler, D. (2019). Accumulation of Nucleolar Inorganic Polyphosphate Is a Cellular Response to CisplatinInduced Apoptosis. Front Oncol, 9, 1410. doi: 10.3389/fonc.2019.01410

[10] Ruiz, F. A., Lea, C. R., Oldfield, E., \& Docampo, R. (2004). Human platelet dense granules contain polyphosphate and are similar to acidocalcisomes of bacteria and unicellular eukaryotes. J Biol Chem, 279(43), 44250-44257. doi: 10.1074/jbc.M406261200

[11] Austin, S., \& Mayer, A. (2020). Phosphate Homeostasis - A Vital Metabolic Equilibrium Maintained Through the INPHORS Signaling Pathway. Front Microbiol, 11, 1367. doi: $10.3389 /$ fmicb.2020.01367

[12] Desfougeres, Y., Neumann, H., \& Mayer, A. (2016). Organelle size control - increasing vacuole content activates SNAREs to augment organelle volume through homotypic fusion. J Cell Sci, 129(14), 2817-2828. doi: 10.1242/jcs.184382

[13] Smith, S. A., Mutch, N. J., Baskar, D., Rohloff, P., Docampo, R., \& Morrissey, J. H. (2006). Polyphosphate modulates blood coagulation and fibrinolysis. Proc Natl Acad Sci US A, 103(4), 903-908. doi: 10.1073/pnas.0507195103

[14] Bentley-DeSousa, A., Holinier, C., Moteshareie, H., Tseng, Y. C., Kajjo, S., Nwosu, C., . . Downey, M. (2018). A Screen for Candidate Targets of Lysine Polyphosphorylation Uncovers a Conserved Network Implicated in Ribosome Biogenesis. Cell Rep, 22(13), 3427-3439. doi: 10.1016/j.celrep.2018.02.104 
[15] Kumble, K. D., Ahn, K., \& Kornberg, A. (1996). Phosphohistidyl active sites in polyphosphate kinase of Escherichia coli. Proc Natl Acad Sci U S A, 93(25), 1439114395. doi: 10.1073/pnas.93.25.14391

[16] Zhu, J., Loubery, S., Broger, L., Zhang, Y., Lorenzo-Orts, L., Utz-Pugin, A., . . Hothorn, M. (2020). A genetically validated approach for detecting inorganic polyphosphates in plants. Plant J, 102(3), 507-516. doi: 10.1111/tpj.14642

[17] Zhu, Y., Huang, W., Lee, S. S., \& Xu, W. (2005). Crystal structure of a polyphosphate kinase and its implications for polyphosphate synthesis. EMBO Rep, 6(7), 681-687. doi: 10.1038/sj.embor.7400448

[18] Ogawa, N., DeRisi, J., \& Brown, P. O. (2000). New components of a system for phosphate accumulation and polyphosphate metabolism in Saccharomyces cerevisiae revealed by genomic expression analysis. Mol Biol Cell, 11(12), 4309-4321. doi: 10.1091/mbc.11.12.4309

[19] Harris, M. A., Clark, J., Ireland, A., Lomax, J., Ashburner, M., Foulger, R., . . Gene Ontology, C. (2004). The Gene Ontology (GO) database and informatics resource. Nucleic Acids Res, 32(Database issue), D258-261. doi: 10.1093/nar/gkh036

[20] Cherry, J. M., Hong, E. L., Amundsen, C., Balakrishnan, R., Binkley, G., Chan, E. T., . . . Wong, E. D. (2012). Saccharomyces Genome Database: the genomics resource of budding yeast. Nucleic Acids Res, 40(Database issue), D700-705. doi: 10.1093/nar/gkr1029

[21] Szklarczyk, D., Gable, A. L., Lyon, D., Junge, A., Wyder, S., Huerta-Cepas, J., . . Mering, C. V. (2019). STRING v11: protein-protein association networks with increased coverage, supporting functional discovery in genome-wide experimental datasets. Nucleic Acids Res, 47(D1), D607-D613. doi: 10.1093/nar/gky1131

[22] Gray, M. J., Wholey, W. Y., Wagner, N. O., Cremers, C. M., Mueller-Schickert, A., Hock, N. T., . . Jakob, U. (2014). Polyphosphate is a primordial chaperone. Mol Cell, 53(5), 689-699. doi: 10.1016/j.molcel.2014.01.012

[23] Beaufay, F., Quarles, E., Franz, A., Katamanin, O., Wholey, W. Y., \& Jakob, U. (2020). Polyphosphate Functions In Vivo as an Iron Chelator and Fenton Reaction Inhibitor. mBio, 11(4). doi: 10.1128/mBio.01017-20

[24] Askwith, C., Eide, D., Van Ho, A., Bernard, P. S., Li, L., Davis-Kaplan, S., . . Kaplan, J. (1994). The FET3 gene of S. cerevisiae encodes a multicopper oxidase required for ferrous iron uptake. Cell, 76(2), 403-410. doi: 10.1016/0092-8674(94)90346-8

[25] Drewke, C., \& Ciriacy, M. (1988). Overexpression, purification and properties of alcohol dehydrogenase IV from Saccharomyces cerevisiae. Biochim Biophys Acta, 950(1), 54-60. doi: 10.1016/0167-4781(88)90072-3

[26] Pearce, D. A., \& Sherman, F. (1999). Toxicity of copper, cobalt, and nickel salts is dependent on histidine metabolism in the yeast Saccharomyces cerevisiae. J Bacteriol, 181(16), 4774-4779. doi: 10.1128/JB.181.16.4774-4779.1999

[27] Yuan, D. S. (2000). Zinc-regulated genes in Saccharomyces cerevisiae revealed by transposon tagging. Genetics, 156(1), 45-58. doi: 10.1093/genetics/156.1.45

[28] Teixeira, M. C., Monteiro, P. T., Palma, M., Costa, C., Godinho, C. P., Pais, P., .. . SaCorreia, I. (2018). YEASTRACT: an upgraded database for the analysis of transcription regulatory networks in Saccharomyces cerevisiae. Nucleic Acids Res, 46(D1), D348D353. doi: 10.1093/nar/gkx842 
[29] Martinez-Pastor, M. T., Marchler, G., Schuller, C., Marchler-Bauer, A., Ruis, H., \& Estruch, F. (1996). The Saccharomyces cerevisiae zinc finger proteins Msn2p and Msn4p are required for transcriptional induction through the stress response element (STRE). EMBO $J, 15(9), 2227-2235$.

[30] Schmitt, A. P., \& McEntee, K. (1996). Msn2p, a zinc finger DNA-binding protein, is the transcriptional activator of the multistress response in Saccharomyces cerevisiae. Proc Natl Acad Sci U S A, 93(12), 5777-5782. doi: 10.1073/pnas.93.12.5777

[31] Pfanzagl, V., Gorner, W., Radolf, M., Parich, A., Schuhmacher, R., Strauss, J., ... Schuller, C. (2018). A constitutive active allele of the transcription factor Msn2 mimicking low PKA activity dictates metabolic remodeling in yeast. Mol Biol Cell, 29(23), 2848-2862. doi: 10.1091/mbc.E18-06-0389

[32] Durchschlag, E., Reiter, W., Ammerer, G., \& Schuller, C. (2004). Nuclear localization destabilizes the stress-regulated transcription factor Msn2. J Biol Chem, 279(53), 5542555432. doi: 10.1074/jbc.M407264200

[33] Gorner, W., Durchschlag, E., Wolf, J., Brown, E. L., Ammerer, G., Ruis, H., \& Schuller, C. (2002). Acute glucose starvation activates the nuclear localization signal of a stressspecific yeast transcription factor. EMBO J, 21(1-2), 135-144. doi: 10.1093/emboj/21.1.135

[34] Ma, L., Ho, K., Piggott, N., Luo, Z., \& Measday, V. (2012). Interactions between the kinetochore complex and the protein kinase A pathway in Saccharomyces cerevisiae. G3 (Bethesda), 2(7), 831-841. doi: 10.1534/g3.112.002675

[35] Lallet, S., Garreau, H., Poisier, C., Boy-Marcotte, E., \& Jacquet, M. (2004). Heat shockinduced degradation of Msn2p, a Saccharomyces cerevisiae transcription factor, occurs in the nucleus. Mol Genet Genomics, 272(3), 353-362. doi: 10.1007/s00438-004-1063-z

[36] Lee, P., Cho, B. R., Joo, H. S., \& Hahn, J. S. (2008). Yeast Yak1 kinase, a bridge between PKA and stress-responsive transcription factors, Hsf1 and Msn2/Msn4. Mol Microbiol, 70(4), 882-895. doi: 10.1111/j.1365-2958.2008.06450.x

[37] Capaldi, A. P., Kaplan, T., Liu, Y., Habib, N., Regev, A., Friedman, N., \& O'Shea, E. K. (2008). Structure and function of a transcriptional network activated by the MAPK Hog1. Nat Genet, 40(11), 1300-1306. doi: 10.1038/ng.235

[38] Lee, P., Paik, S. M., Shin, C. S., Huh, W. K., \& Hahn, J. S. (2011). Regulation of yeast Yak1 kinase by PKA and autophosphorylation-dependent 14-3-3 binding. Mol Microbiol, 79(3), 633-646. doi: 10.1111/j.1365-2958.2010.07471.x

[39] Denoncourt, A., \& Downey, M. (2021). Model systems for studying polyphosphate biology: a focus on microorganisms. Curr Genet. doi: 10.1007/s00294-020-01148-x

[40] Lonetti, A., Szijgyarto, Z., Bosch, D., Loss, O., Azevedo, C., \& Saiardi, A. (2011). Identification of an evolutionarily conserved family of inorganic polyphosphate endopolyphosphatases. J Biol Chem, 286(37), 31966-31974. doi: 10.1074/jbc.M111.266320

[41] Tammenkoski, M., Koivula, K., Cusanelli, E., Zollo, M., Steegborn, C., Baykov, A. A., \& Lahti, R. (2008). Human metastasis regulator protein H-prune is a short-chain exopolyphosphatase. Biochemistry, 47(36), 9707-9713. doi: 10.1021/bi8010847

[42] Samper-Martin, B., Sarrias, A., Lazaro, B., Perez-Montero, M., Rodriguez-Rodriguez, R., Ribeiro, M. P. C., . . . Bru, S. (2021). Polyphosphate degradation by Nudt3-Zn(2+) mediates oxidative stress response. Cell Rep, 37(7), 110004. doi: 10.1016/j.celrep.2021.110004 
[43] Azevedo, C., Desfougeres, Y., Jiramongkol, Y., Partington, H., Trakansuebkul, S., Singh, J., ... Saiardi, A. (2020). Development of a yeast model to study the contribution of vacuolar polyphosphate metabolism to lysine polyphosphorylation. J Biol Chem, 295(6), 1439-1451. doi: 10.1074/jbc.RA119.011680

[44] Bentley-DeSousa, A., \& Downey, M. (2019). From underlying chemistry to therapeutic potential: open questions in the new field of lysine polyphosphorylation. Curr Genet, 65(1), 57-64. doi: 10.1007/s00294-018-0854-4

[45] Moreno, B., Urbina, J. A., Oldfield, E., Bailey, B. N., Rodrigues, C. O., \& Docampo, R. (2000). 31P NMR spectroscopy of Trypanosoma brucei, Trypanosoma cruzi, and Leishmania major. Evidence for high levels of condensed inorganic phosphates. $J$ Biol Chem, 275(37), 28356-28362. doi: 10.1074/jbc.M003893200

[46] Negreiros, R. S., Lander, N., Huang, G., Cordeiro, C. D., Smith, S. A., Morrissey, J. H., \& Docampo, R. (2018). Inorganic polyphosphate interacts with nucleolar and glycosomal proteins in trypanosomatids. Mol Microbiol, 110(6), 973-994. doi: 10.1111/mmi.14131

[47] Travers, R. J., Smith, S. A., \& Morrissey, J. H. (2015). Polyphosphate, platelets, and coagulation. Int J Lab Hematol, 37 Suppl 1, 31-35. doi: 10.1111/ijlh.12349

[48] Smith, S. A., Choi, S. H., Davis-Harrison, R., Huyck, J., Boettcher, J., Rienstra, C. M., \& Morrissey, J. H. (2010). Polyphosphate exerts differential effects on blood clotting, depending on polymer size. Blood, 116(20), 4353-4359. doi: 10.1182/blood-2010-01266791

[49] Roewe, J., Stavrides, G., Strueve, M., Sharma, A., Marini, F., Mann, A., . . Bosmann, M. (2020). Bacterial polyphosphates interfere with the innate host defense to infection. Nat Commun, 11(1), 4035. doi: 10.1038/s41467-020-17639-x

[50] Azevedo, C., Livermore, T., \& Saiardi, A. (2015). Protein polyphosphorylation of lysine residues by inorganic polyphosphate. $\mathrm{Mol}$ Cell, 58(1), 71-82. doi: 10.1016/j.molcel.2015.02.010

[51] Conrad, M., Schothorst, J., Kankipati, H. N., Van Zeebroeck, G., Rubio-Texeira, M., \& Thevelein, J. M. (2014). Nutrient sensing and signaling in the yeast Saccharomyces cerevisiae. FEMS Microbiol Rev, 38(2), 254-299. doi: 10.1111/1574-6976.12065

[52] Denis-Duphil, M., Lecaer, J. P., Hardie, D. G., \& Carrey, E. A. (1990). Yeast carbamoylphosphate-synthetase--aspartate-transcarbamylase multidomain protein is phosphorylated in vitro by cAMP-dependent protein kinase. Eur J Biochem, 193(2), 581-587. doi: 10.1111/j.1432-1033.1990.tb19376.x

[53] Urita, A., Ishibashi, Y., Kawaguchi, R., Yanase, Y., \& Tani, M. (2021). Crosstalk between protein kinase A and the HOG pathway under impaired biosynthesis of complex sphingolipids in budding yeast. FEBS J. doi: 10.1111/febs.16188

[54] Smith, A., Ward, M. P., \& Garrett, S. (1998). Yeast PKA represses Msn2p/Msn4pdependent gene expression to regulate growth, stress response and glycogen accumulation. EMBO J, 17(13), 3556-3564. doi: 10.1093/emboj/17.13.3556

[55] Garrett, S., \& Broach, J. (1989). Loss of Ras activity in Saccharomyces cerevisiae is suppressed by disruptions of a new kinase gene, YAKI, whose product may act downstream of the cAMP-dependent protein kinase. Genes Dev, 3(9), 1336-1348. doi: 10.1101/gad.3.9.1336

[56] Zurita-Martinez, S. A., \& Cardenas, M. E. (2005). Tor and cyclic AMP-protein kinase A: two parallel pathways regulating expression of genes required for cell growth. Eukaryot Cell, 4(1), 63-71. doi: 10.1128/EC.4.1.63-71.2005 
[57] Kulakovskaya, T. V., Lichko, L. P., Vagabov, V. M., \& Kulaev, I. S. (2010). Inorganic polyphosphates in mitochondria. Biochemistry (Mosc), 75(7), 825-831. doi:

$10.1134 / \mathrm{s} 0006297910070035$

[58] Bru, S., Martinez-Lainez, J. M., Hernandez-Ortega, S., Quandt, E., Torres-Torronteras, J., Marti, R., . . Clotet, J. (2016). Polyphosphate is involved in cell cycle progression and genomic stability in Saccharomyces cerevisiae. Mol Microbiol, 101(3), 367-380. doi: 10.1111/mmi.13396

[59] Hussain, M., Leibowitz, M. J., \& Lenard, J. (1987). Killing of Saccharomyces cerevisiae by the lysosomotropic detergent N-dodecylimidazole. Antimicrob Agents Chemother, 31(4), 512-517. doi: 10.1128/AAC.31.4.512

[60] Eastwood, M. D., Cheung, S. W., \& Meneghini, M. D. (2013). Programmed nuclear destruction in yeast: self-eating by vacuolar lysis. Autophagy, 9(2), 263-265. doi: 10.4161/auto.22881

[61] Bondy-Chorney, E., Abramchuk, I., Nasser, R., Holinier, C., Denoncourt, A., Baijal, K., .. . Downey, M. (2020). A Broad Response to Intracellular Long-Chain Polyphosphate in Human Cells. Cell Rep, 33(4), 108318. doi: 10.1016/j.celrep.2020.108318

[62] Ki, S., Sugihara, F., Kasahara, K., Tochio, H., Shirakawa, M., \& Kokubo, T. (2007). Magnetic resonance-based visualization of gene expression in mammalian cells using a bacterial polyphosphate kinase reporter gene. Biotechniques, 42(2), 209-215. doi: 10.2144/000112319

[63] Nistala, H., Dronzek, J., Gonzaga-Jauregui, C., Chim, S. M., Rajamani, S., Nuwayhid, S., . . . Economides, A. N. (2021). NMIHBA results from hypomorphic PRUNE1 variants that lack short-chain exopolyphosphatase activity. Hum Mol Genet, 29(21), 3516-3531. doi: 10.1093/hmg/ddaa237

[64] Goldstein, A. L., \& McCusker, J. H. (1999). Three new dominant drug resistance cassettes for gene disruption in Saccharomyces cerevisiae. Yeast, 15(14), 1541-1553. doi: 10.1002/(SICI)1097-0061(199910)15:14<1541::AID-YEA476>3.0.CO;2-K

[65] Longtine, M. S., McKenzie, A., 3rd, Demarini, D. J., Shah, N. G., Wach, A., Brachat, A., . . . Pringle, J. R. (1998). Additional modules for versatile and economical PCR-based gene deletion and modification in Saccharomyces cerevisiae. Yeast, 14(10), 953-961. doi: 10.1002/(SICI)1097-0061(199807)14:10<953::AID-YEA293>3.0.CO;2-U

[66] McCarthy, L., Bentley-DeSousa, A., Denoncourt, A., Tseng, Y. C., Gabriel, M., \& Downey, M. (2020). Proteins required for vacuolar function are targets of lysine polyphosphorylation in yeast. FEBS Lett, 594(1), 21-30. doi: 10.1002/1873-3468.13588

[67] Bru, S., Samper-Martin, B., Quandt, E., Hernandez-Ortega, S., Martinez-Lainez, J. M., Gari, E., . . . Clotet, J. (2017). Polyphosphate is a key factor for cell survival after DNA damage in eukaryotic cells. DNA Repair (Amst), 57, 171-178. doi: 10.1016/j.dnarep.2017.08.001

[68] Smith, S. A., \& Morrissey, J. H. (2007). Sensitive fluorescence detection of polyphosphate in polyacrylamide gels using 4',6-diamidino-2-phenylindol. Electrophoresis, 28(19), 3461-3465. doi: 10.1002/elps.200700041

[69] Kessner, D., Chambers, M., Burke, R., Agus, D., \& Mallick, P. (2008). ProteoWizard: open source software for rapid proteomics tools development. Bioinformatics, 24(21), 25342536. doi: 10.1093/bioinformatics/btn323

[70] Craig, R., \& Beavis, R. C. (2004). TANDEM: matching proteins with tandem mass spectra. Bioinformatics, 20(9), 1466-1467. doi: 10.1093/bioinformatics/bth092 
[71] Bairoch, A., \& Boeckmann, B. (1994). The SWISS-PROT protein sequence data bank: current status. Nucleic Acids Res, 22(17), 3578-3580.

[72] Howe, K. L., Achuthan, P., Allen, J., Allen, J., Alvarez-Jarreta, J., Amode, M. R., . . . Flicek, P. (2021). Ensemb1 2021. Nucleic Acids Res, 49(D1), D884-D891. doi: 10.1093/nar/gkaa942

[73] Benjamini, Y., \& Hochberg, Y. (1995). Controlling the false discovery rate: a practical and powerful approach to multiple testing. Journal of the Royal Statistical Society, Series B, 57 (1), 289-300. MR 1325392.

[74] Ashburner, M., Ball, C. A., Blake, J. A., Botstein, D., Butler, H., Cherry, J. M., . . . Sherlock, G. (2000). Gene ontology: tool for the unification of biology. The Gene Ontology Consortium. Nat Genet, 25(1), 25-29. doi: 10.1038/75556

[75] Bauer, S., Grossmann, S., Vingron, M., \& Robinson, P. N. (2008). Ontologizer 2.0--a multifunctional tool for GO term enrichment analysis and data exploration. Bioinformatics, 24(14), 1650-1651. doi: 10.1093/bioinformatics/btn250 
bioRxiv preprint doi: https://doi.org/10.1101/2022.02.02.478728; this version posted February 2, 2022. The copyright holder for this preprint (which was not certified by peer review) is the author/funder, who has granted bioRxiv a license to display the preprint in perpetuity. It is made available under aCC-BY-NC 4.0 International license.

\section{Figure 1}

A



B

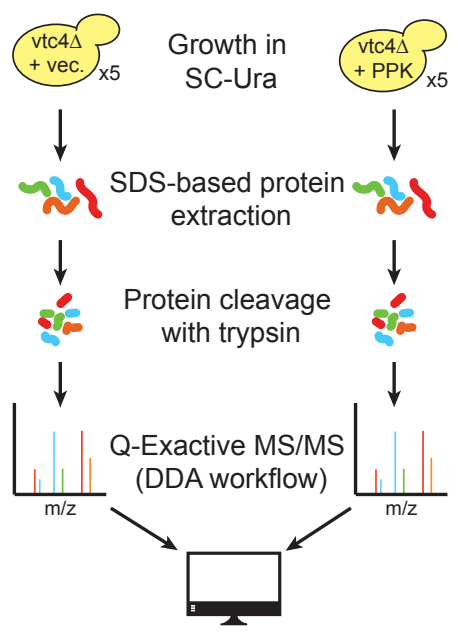

Data analysis in Scaffold

C

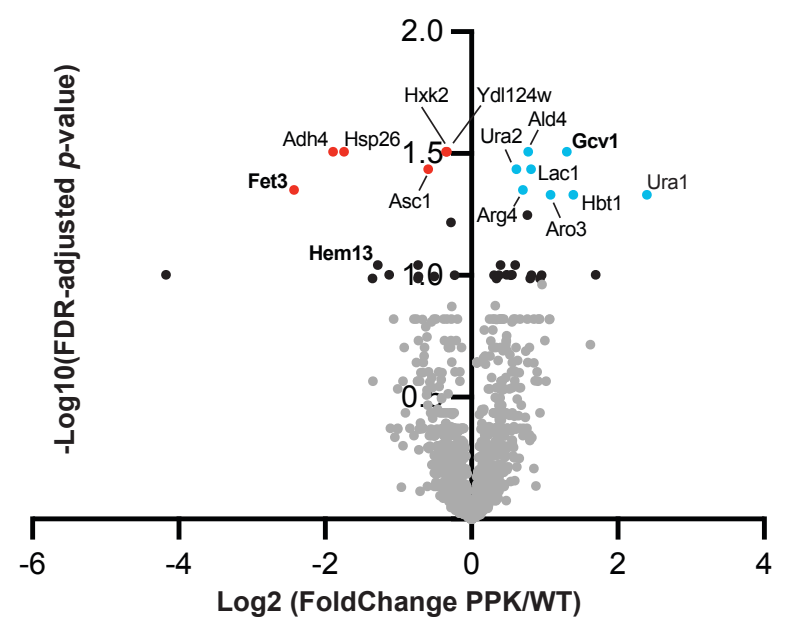

D

\begin{tabular}{llr} 
Protein & Function & $\begin{array}{r}\text { Log2FC } \\
\text { (PPK/WT) }\end{array}$ \\
\hline Fet3 & Ferro-O2-oxidoreductase (iron uptake) & -2.42 \\
Adh4 & Alcohol dehydrogenase & -1.89 \\
Hsp26 & Heat shock protein & -1.74 \\
Asc1 & 40S ribosome component & -0.59 \\
Hxk2 & Hexokinase isozyme (glucose metabolism) & -0.35 \\
Ydl124w & Alpha-keto amide reductase & -0.33 \\
Snl1 & Hsp70 co-chaperone & N/A \\
Rpl22b & Large ribosomal subunit protein & +0.62 \\
Arg4 & Arginine biosynthesis & +0.70 \\
Aro3 & Aromatic amino acid biosynthesis & +0.77 \\
Ald4 & Aldehyde dehydrogenase (mitochondrial) & +0.81 \\
Ura2 & Pryimidine biosynthesis & +1.08 \\
Lac1 & Ceramide synthesis & +1.30 \\
Gcv1 & Glycine decarboxylase complex (mitochondrial) & +1.39 \\
Hbt1 & Cell morphogenesis & +2.39 \\
Ura1 & Pyrimidine biosynthesis & N/A \\
PPK & E. coli polyP kinase &
\end{tabular}


bioRxiv preprint doi: https://doi.org/10.1101/2022.02.02.478728; this version posted February 2, 2022. The copyright holder for this preprint (which was not certified by peer review) is the author/funder, who has granted bioRxiv a license to display the preprint in perpetuity. It is made available under aCC-BY-NC 4.0 International license.

Figure 2

A

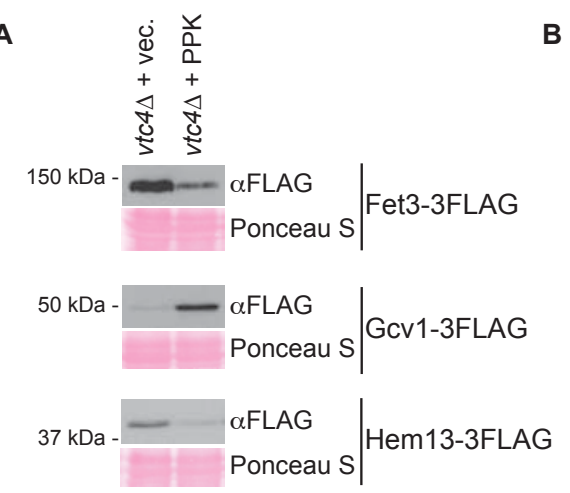

D

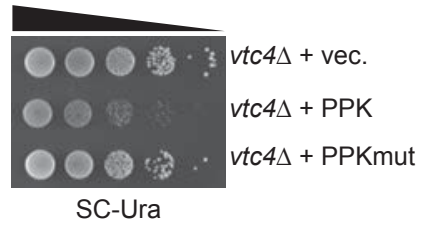

B

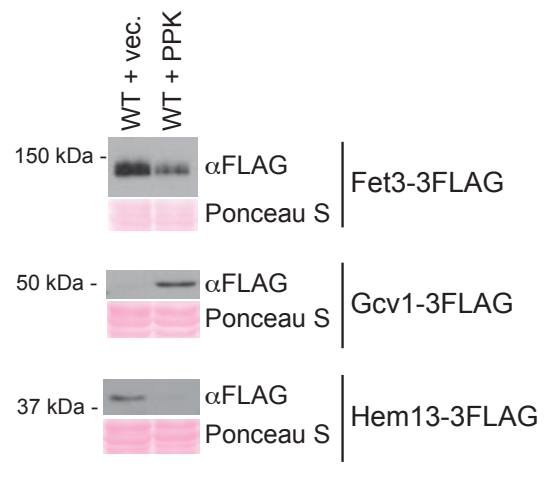

E

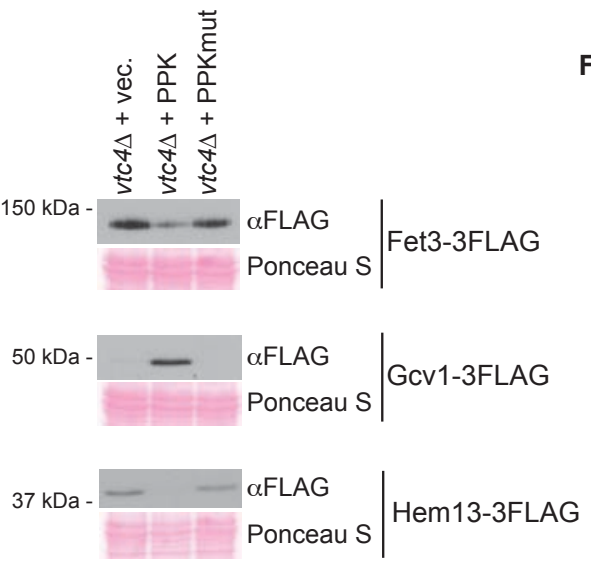

C

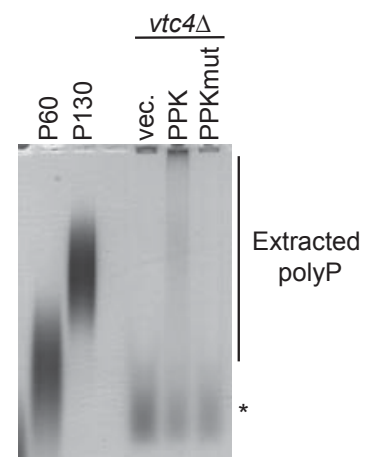

$\mathbf{F}$

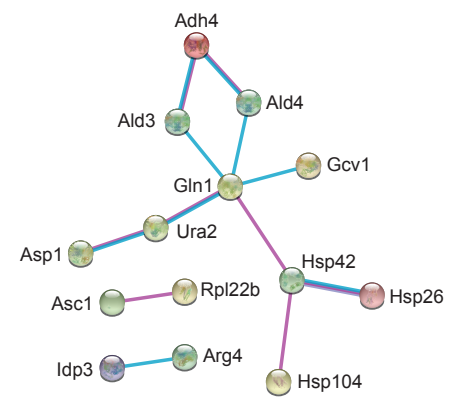




\section{Figure 3}

A

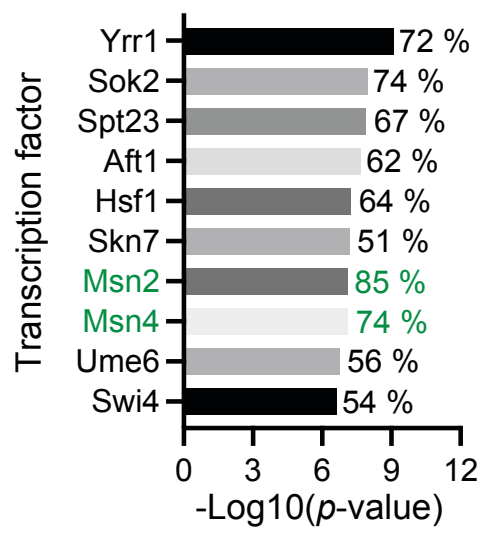

C

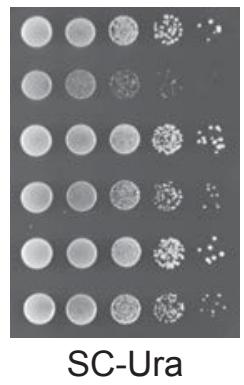

WT + vec.

$\mathrm{WT}+\mathrm{PPK}$

$m s n 2 \Delta m s n 4 \Delta(1)+$ vec.

$m s n 2 \Delta m s n 4 \Delta$

(1) + PPK

$m s n 2 \Delta m s n 4 \Delta$ $m s n 2 \Delta m s n 4 \Delta$

(2) + vec.

(2) + PPK

SC-Ura

B Cytoplasm Nucleus

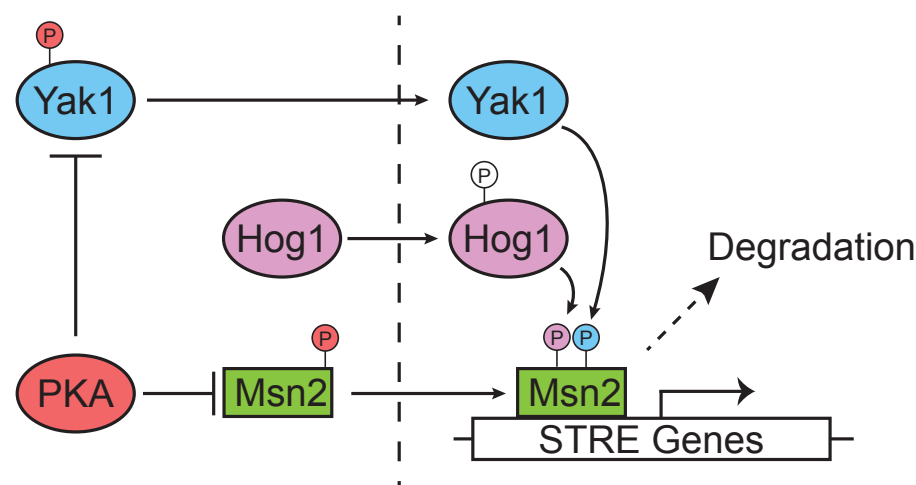

D

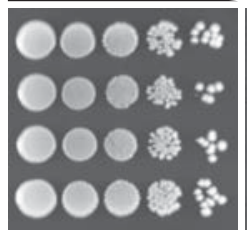

Glucose

HA-PPK Off

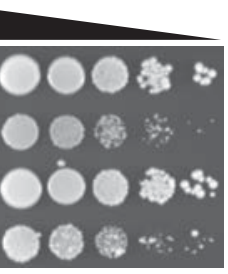

vtc $4 \Delta+$ cont.

$v t c 4 \Delta+\mathrm{HA}-\mathrm{PPK}$

$W T+$ cont.

WT + HA-PPK

Galactose

HA-PPK On

\begin{tabular}{|l|l|l|}
\multicolumn{1}{l}{} & \multicolumn{1}{l}{$\rightarrow$} \\
\hline GALpr & $H A-P P K$ \\
\hline
\end{tabular}

E

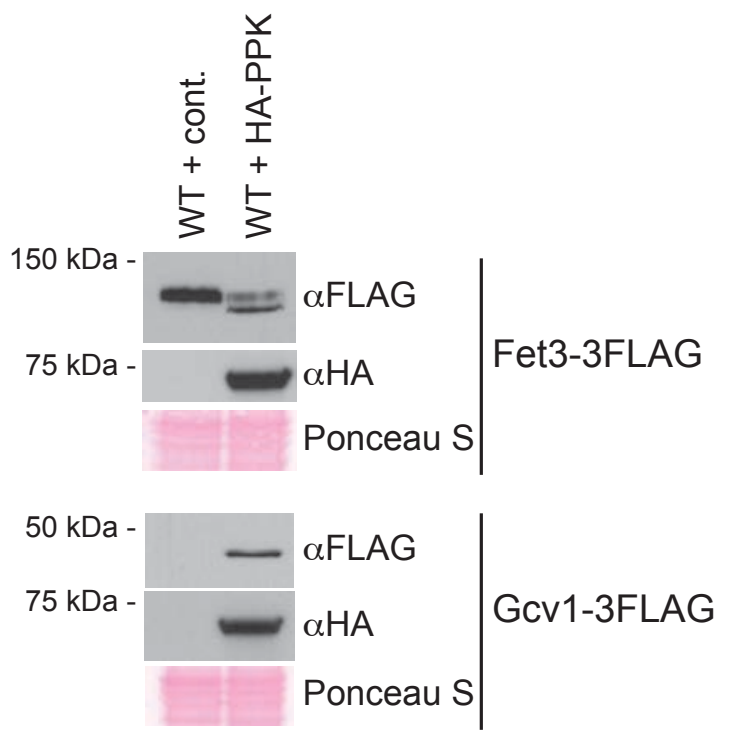

F

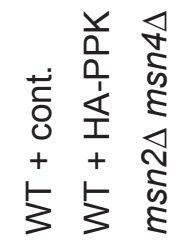

$100 \mathrm{kDa}-$

aMsn2

$\alpha \operatorname{Cdc55}$ (Load)

$100 \mathrm{kDa}-$

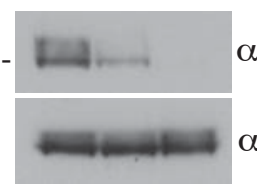

$\alpha p-C R E B(p-M s n 2)$

aCdc55 (Load) 


\section{Figure 4}

A

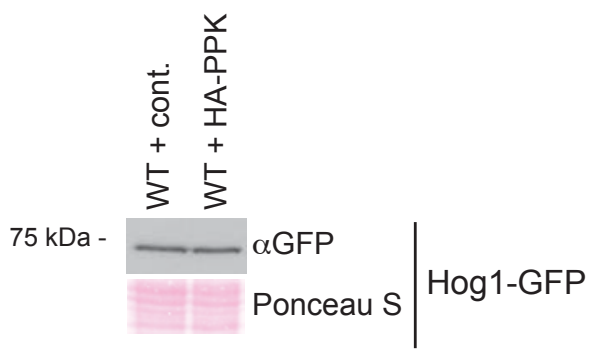

C

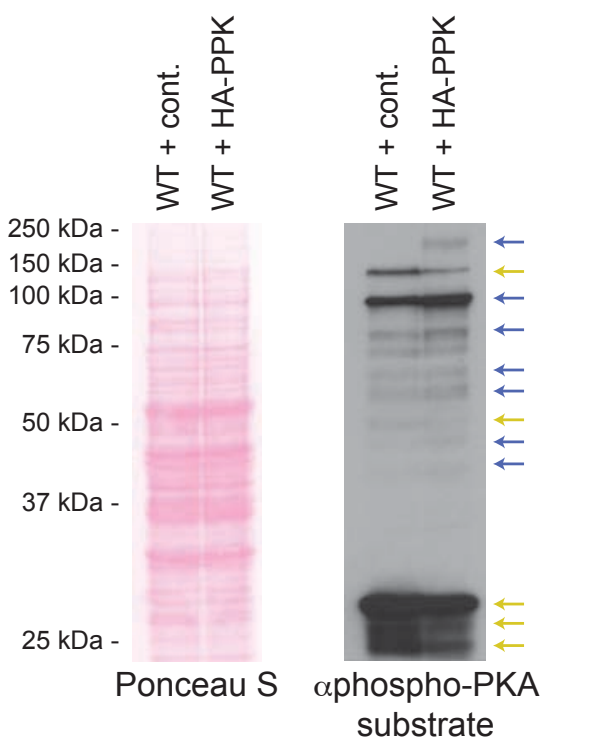

B

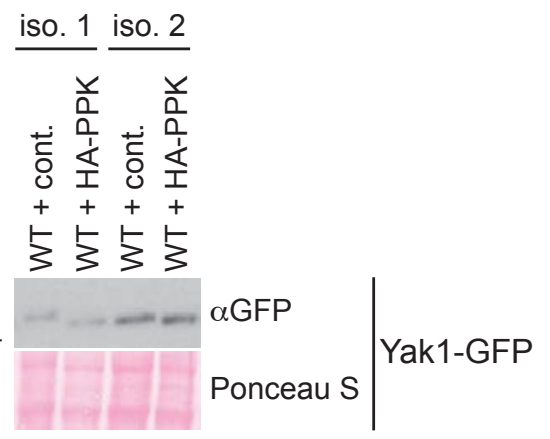

D

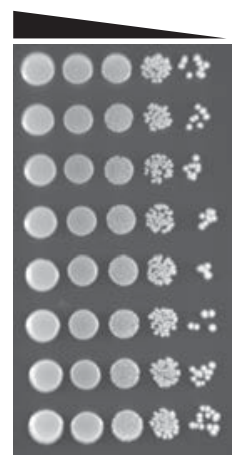

Glu (HA-PPK Off)

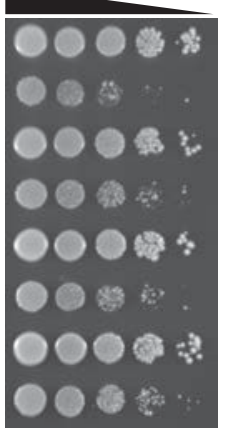

WT + cont. WT + HA-PPK hog $1 \Delta+$ cont. hog1 $1 \Delta+$ HA-PPK yak1 $1 \Delta+$ cont. yak1 $1 \Delta+$ HA-PPK hog $1 \Delta$ yak1 $1 \Delta+$ cont. hog $1 \Delta$ yak1 $1 \Delta+$ HA-PPK
(HA-PPK On) 
bioRxiv preprint doi: https://doi.org/10.1101/2022.02.02.478728; this version posted February 2, 2022. The copyright holder for this preprint (which was not certified by peer review) is the author/funder, who has granted bioRxiv a license to display the preprint in perpetuity. It is made available under aCC-BY-NC 4.0 International license.

\section{Figure 5}

A

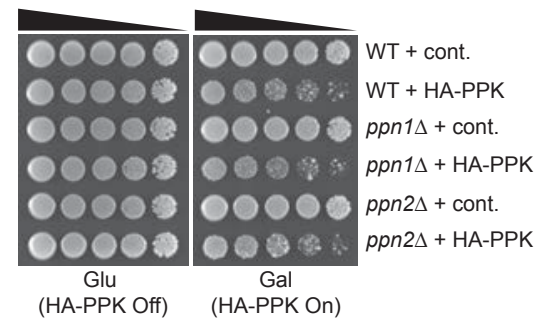

C

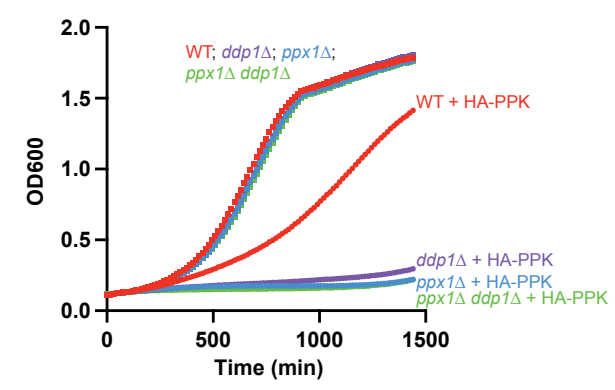

E

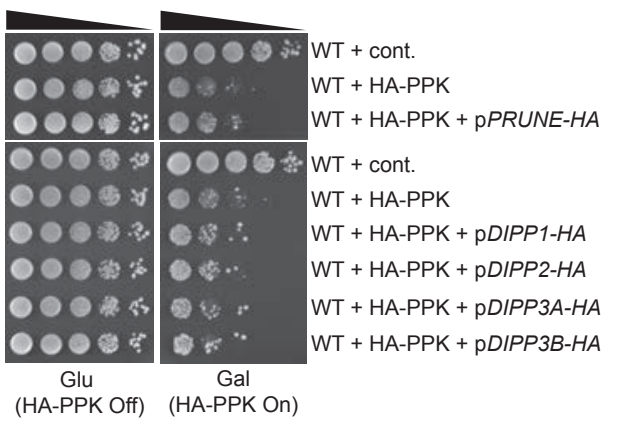

B

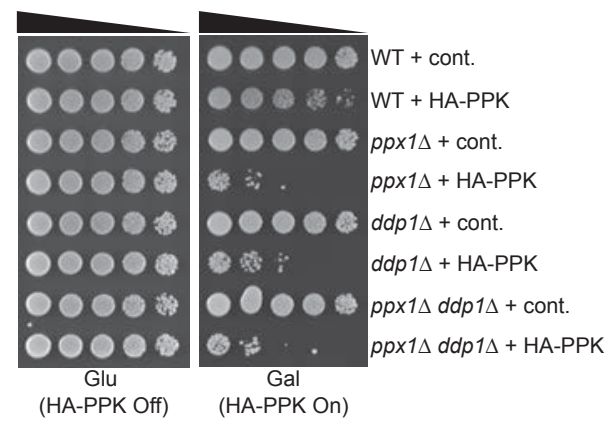

D

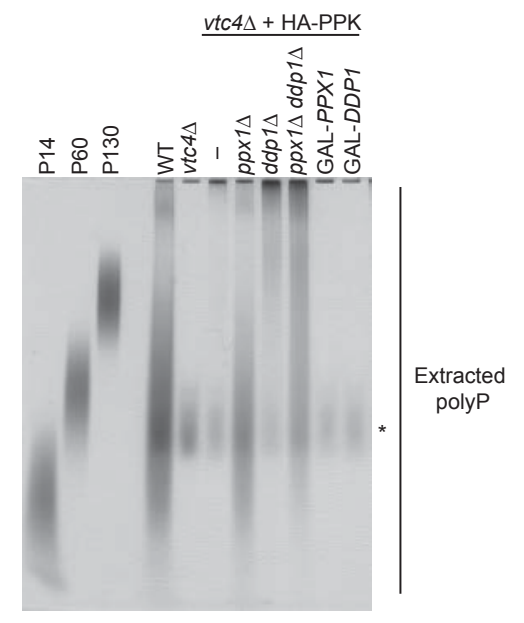

$\mathbf{F}$

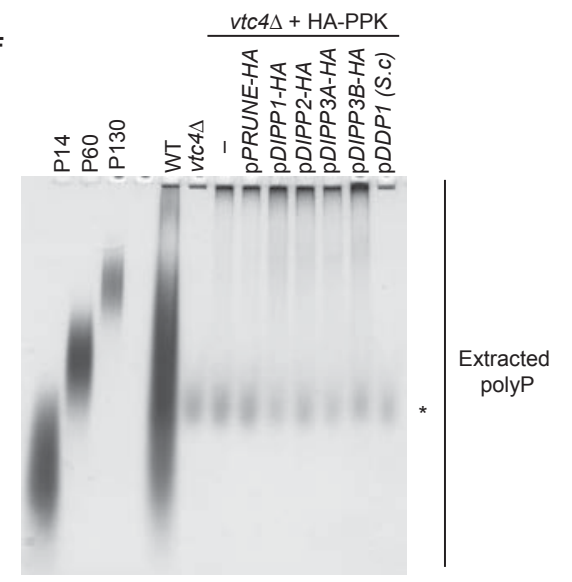

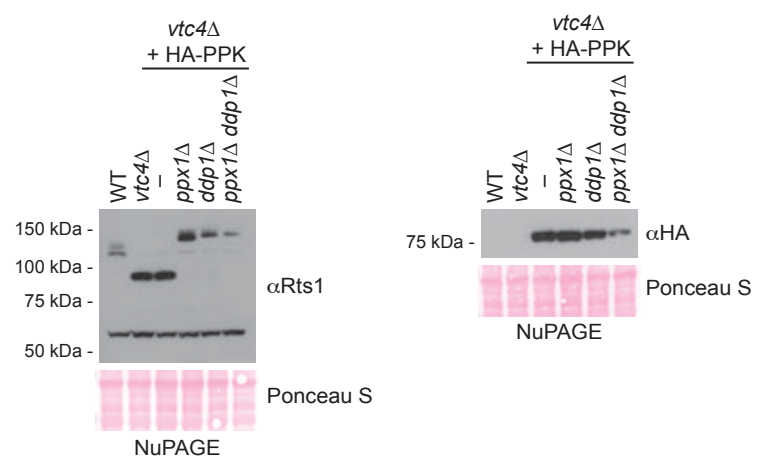


bioRxiv preprint doi: https://doi.org/10.1101/2022.02.02.478728; this version posted February 2, 2022. The copyright holder for this preprint (which was not certified by peer review) is the author/funder, who has granted bioRxiv a license to display the preprint in perpetuity. It is made available under aCC-BY-NC 4.0 International license.

\section{Figure 6}

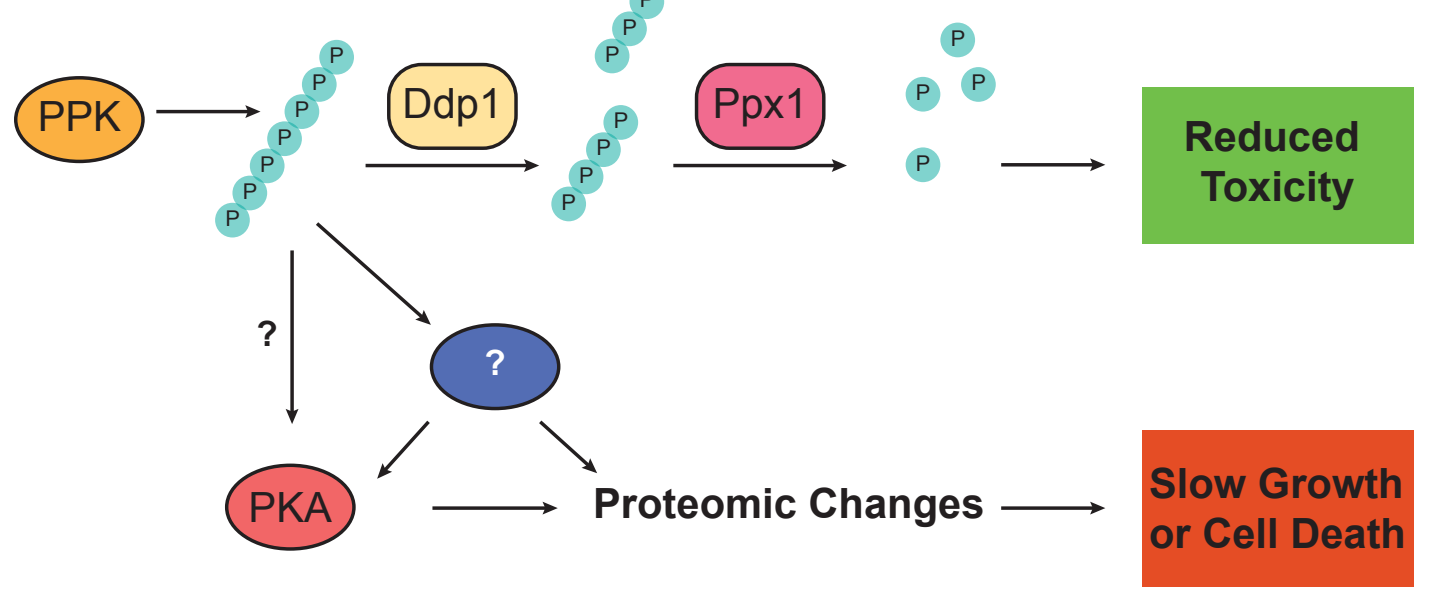


bioRxiv preprint doi: https://doi.org/10.1101/2022.02.02.478728; this version posted February 2, 2022. The copyright holder for this preprint (which was not certified by peer review) is the author/funder, who has granted bioRxiv a license to display the preprint in perpetuity. It is made available under aCC-BY-NC 4.0 International license.

\section{Supplementary Figure 1}

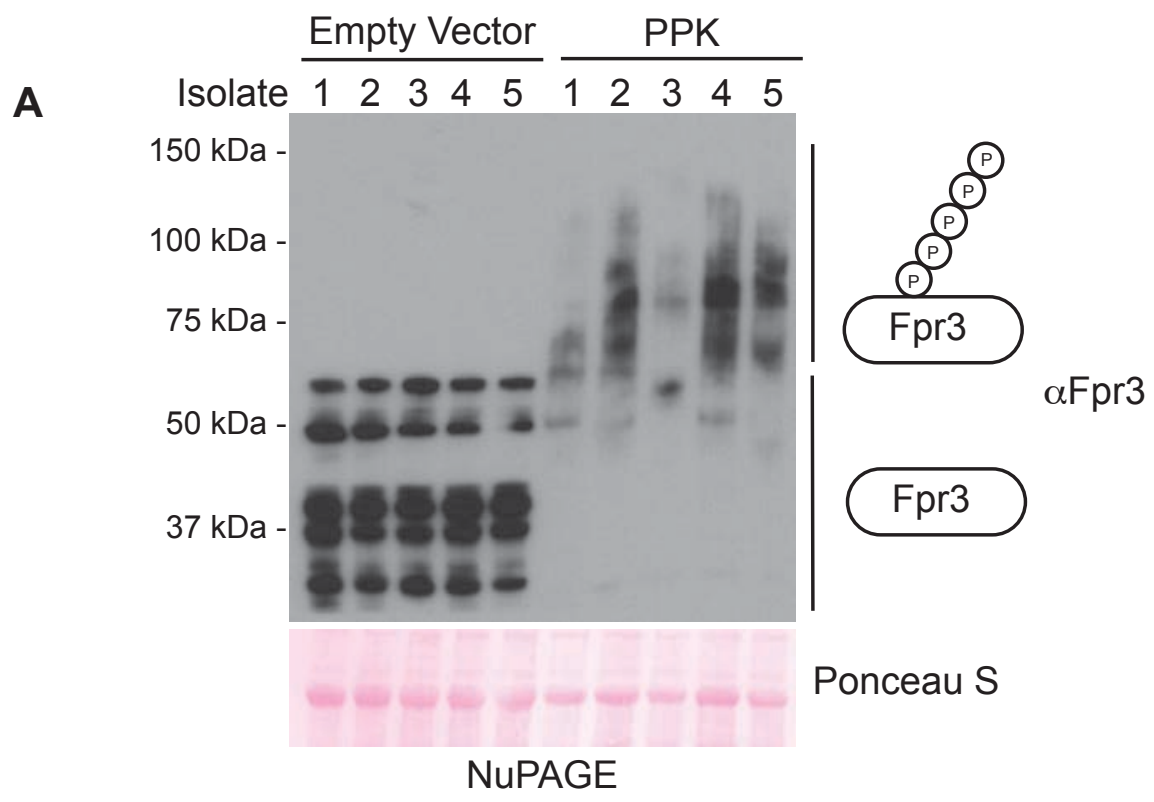




\section{Supplementary Figure 2}

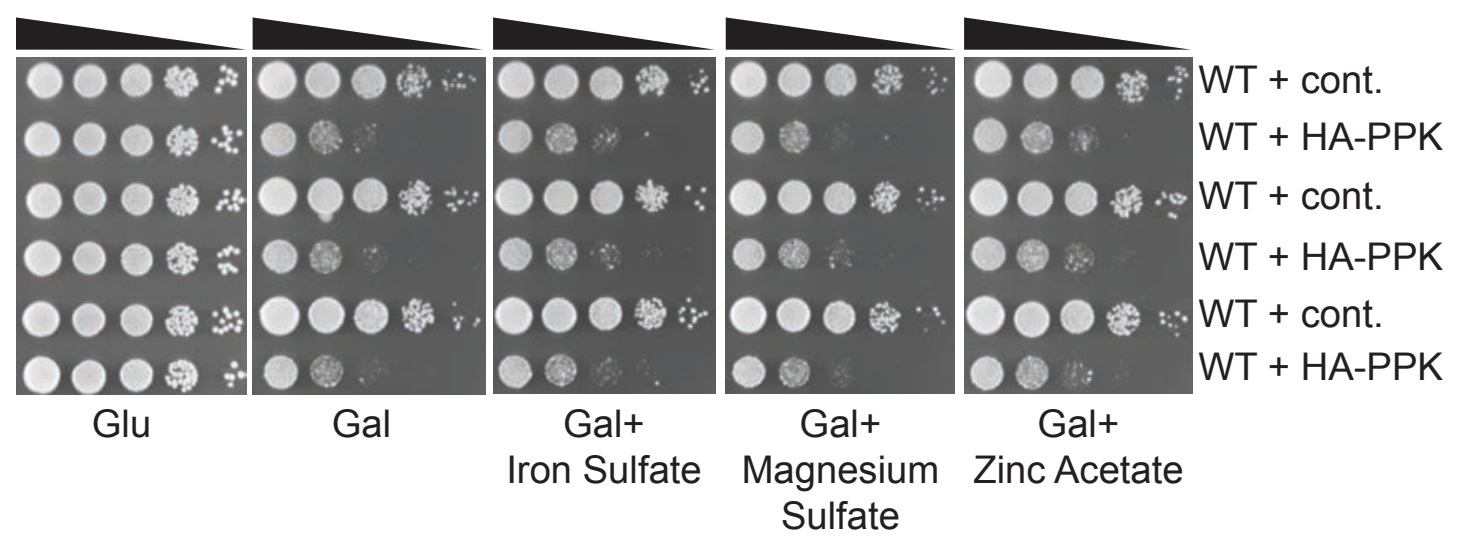


bioRxiv preprint doi: https://doi.org/10.1101/2022.02.02 478728; this version posted February 2, 2022. The copyright holder for this preprint (which was not certified by peer review) is the author/funder, who has granted bioRxiv a license to display the preprint in perpetuity. It is made available under aCC-BY-NC 4.0 International license.

\section{Supplementary Figure 3}

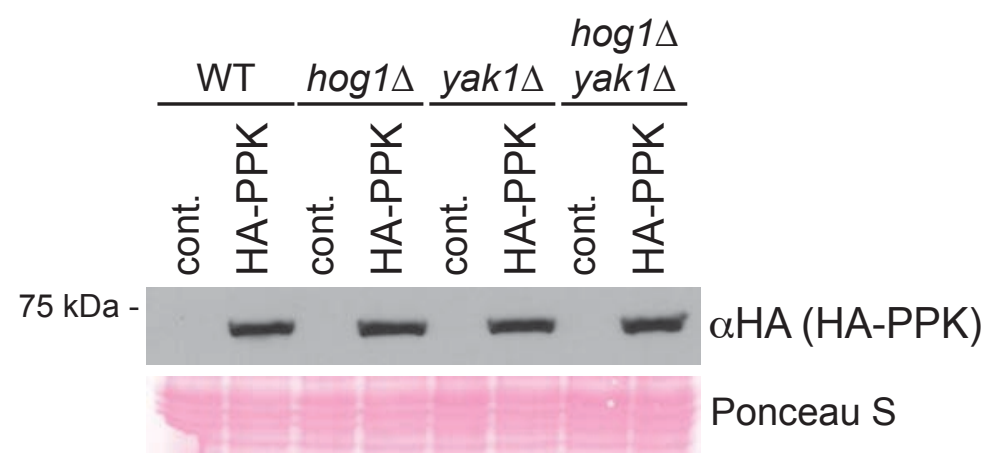


bioRxiv preprint doi: https://doi.org/10.1101/2022.02.02 478728; this version posted February 2, 2022. The copyright holder for this preprint (which was not certified by peer review) is the author/funder, who has granted bioRxiv a license to display the preprint in perpetuity. It is made available under aCC-BY-NC 4.0 International license.

\section{Supplementary Figure 4}

A

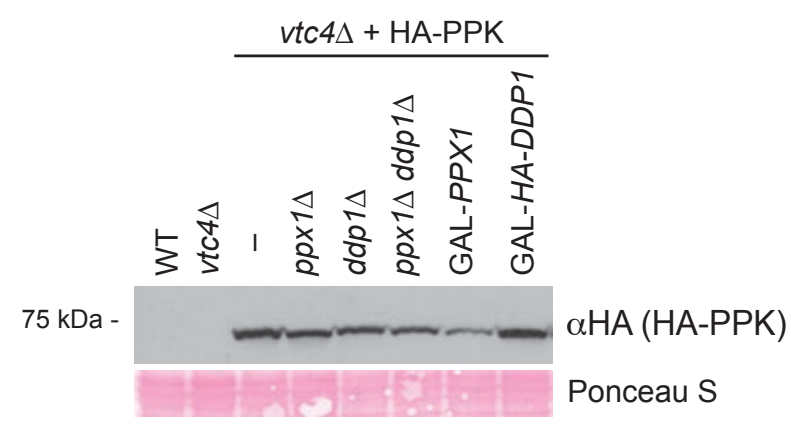

B

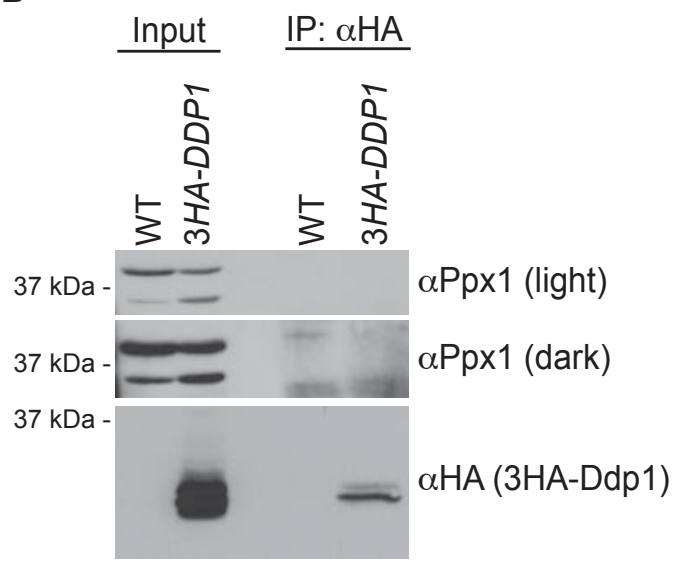


bioRxiv preprint doi: https://doi.org/10.1101/2022.02.02.478728; this version posted February 2, 2022. The copyright holder for this preprint (which was not certified by peer review) is the author/funder, who has granted bioRxiv a license to display the preprint in perpetuity. It is made available under aCC-BY-NC 4.0 International license.

\section{Supplementary Figure 5}

A

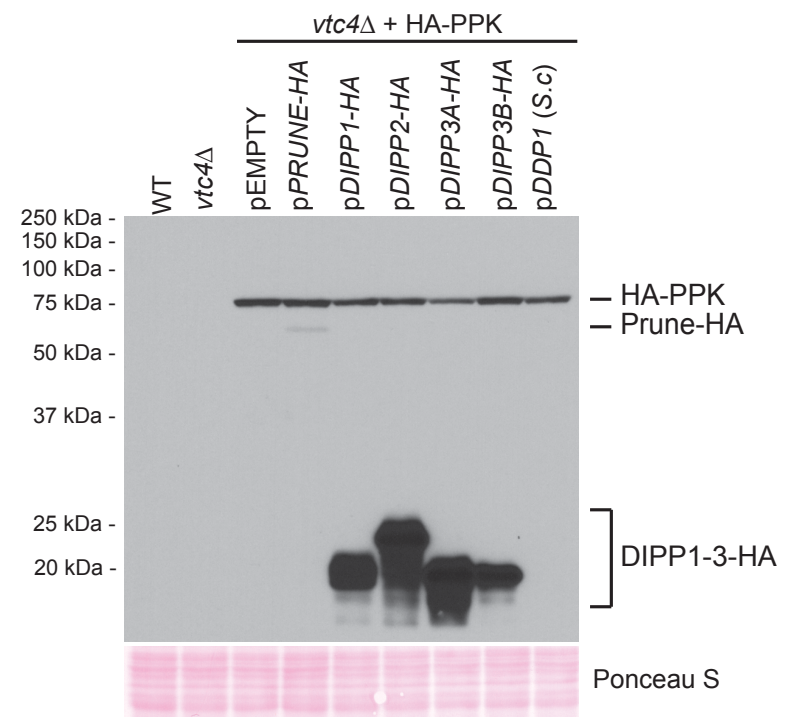

B

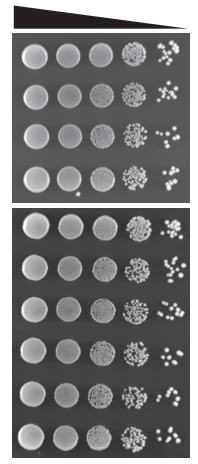

Glu

(HA-PPK Off)

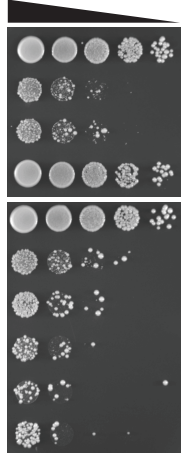

Gal

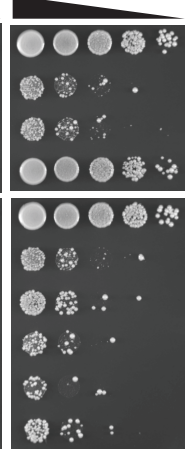

$\mathrm{Gal}+$

$1 \mathrm{~mm}$ Zinc

(HA-PPK On)

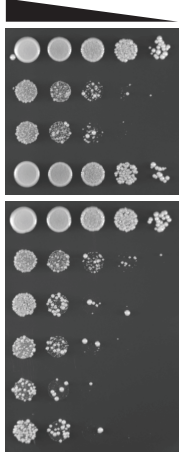

Gal +

$0.4 \mathrm{~mm}$ Zinc

(HA-PPK On)
WT + cont.
HA-PPK
WT + HA-PPK + pPRUNE-HA
WT + HA-PPK + pDDP1 (S.c)
WT + cont.
WT + HA-PPK
WT + HA-PPK + pDIPP1-HA
WT + HA-PPK + pDIPP2-HA
WT + HA-PPK + pDIPP3A-HA
WT + HA-PPK + pDIPP3B-HA

C

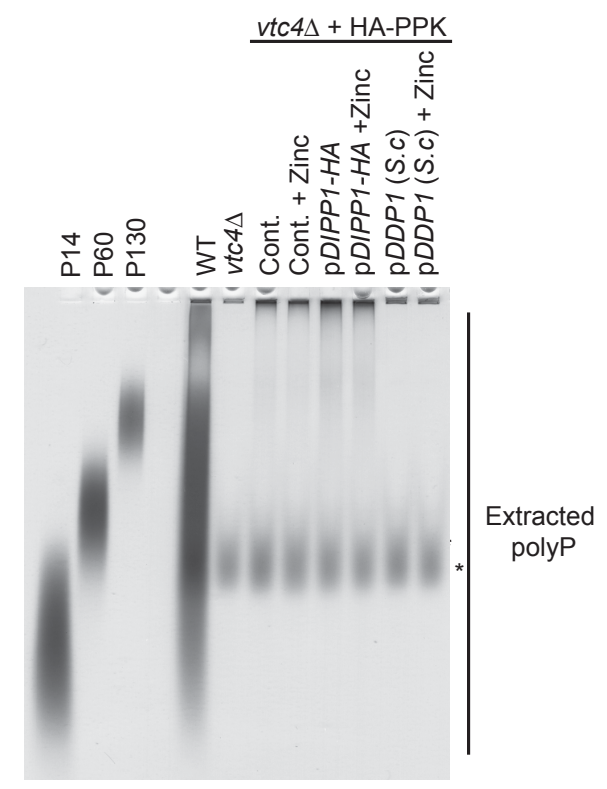

